
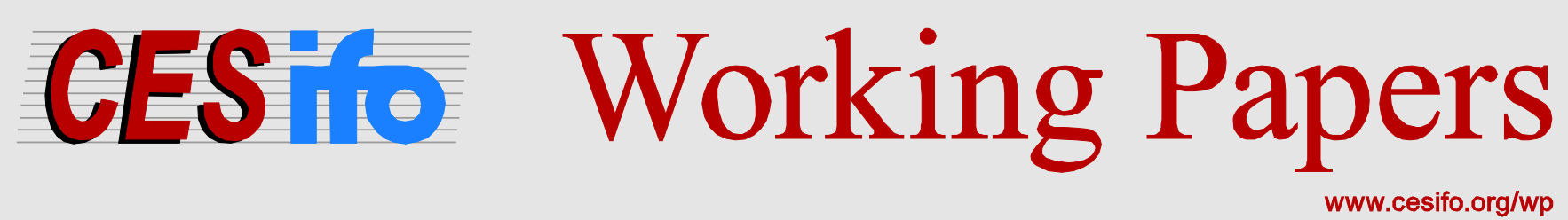

\title{
Buying to Sell: Private Equity Buyouts and Industrial Restructuring
}

\author{
Pehr-Johan Norbäck \\ Lars Persson \\ Joacim Tåg
}

CESIFO WORKING PAPER NO. 4338

CATEGORY 11: INDUSTRIAL ORGANISATION

JULY 2013

An electronic version of the paper may be downloaded

- from the SSRN website:

- from the RePEc website:

WwW.SSRN.com

www.RePEc.org

- from the CESifo website:

www.CESifo-group.org/wp

\section{CESifo}




\title{
Buying to Sell: Private Equity Buyouts and Industrial Restructuring
}

\begin{abstract}
We show how temporary ownership by private equity firms affects industry structure, competition and welfare. Temporary ownership leads to strong investment incentives because equilibrium resale prices are determined by buyers incentives to block rivals from obtaining assets. These incentives benefit consumers, but harm rivals in the industry. Evaluating optimal antitrust policy, we underscore that an active private equity market can aid antitrust authorities by triggering welfare-enhancing mergers and by preventing concentration in the industry. By spreading the cost of specializing in restructuring over multiple markets, private equity firms have stronger incentives than incumbents to invest in acquiring specialized restructuring skills.
\end{abstract}

JEL-Code: G320, G340, L130, L220, L400.

Keywords: antitrust, competition policy, leveraged buyouts, mergers and acquisitions, private equity, temporary ownership.

Pehr-Johan Norbäck

Research Institute of Industrial Economics

(IFN) / Box 55665

Sweden - 10215 Stockholm

pehr-johan.norback@ifn.se

\section{Lars Persson*}

Research Institute of Industrial Economics

(IFN) / Box 55665

Sweden - 10215 Stockholm

lars.persson@ifn.se

\author{
Joacim Tåg \\ Research Institute of Industrial Economics \\ (IFN) / Box 55665 \\ Sweden-10215 Stockholm \\ joacim.tag@ifn.se
}

\section{*corresponding author}

July 12, 2013

Financial support from the Marianne and Marcus Wallenberg Foundation and the Jan Wallander and Tom Hedelius Foundation is gratefully acknowledged. We thank Kevin Amess, Ulf Axelson, Florian Ederer, Ioannis Floros, Richard Gilbert, Denis Gromb, Björn Hansson, Michael Katz, Evgeny Lyandres, Ludovic Phalippou, Gordon Phillips, Ramana Sonti, Yossi Spiegel and seminar participants at the Institute for Financial Research, the Swedish Foundation for Small Business Research, the International Industrial Organization Conference 2009, the 11th Annual SNEE European Integration Conference, the CAF Summer Research Conference (Indian School of Business, Hyderabad), 24th Annual Congress of the European Economic Association, The IFN Stockholm Conference (Vaxholm, 2009 and 2010), the EEA meetings in Oslo 2011 and The Research Institute of Industrial Economics (IFN) for excellent comments and suggestions. We also thank Aron Berg for research assistance. 


\section{Introduction}

During the last decade acquisitions and resales of large firms by private equity funds have become more prevalent. Strömberg (2008) estimates that the value of all private equity buyouts world wide between 1970 and 2000 was $\$ 0.9$ trillion, while the value between 2000 and 2007 was close to $\$ 2.7$ trillion. According to the European Venture Capital Association, around 2100 European companies owned by private equity firms in 2012 and an estimated 541 billion euros was invested by private equity firms in Europe between 2000 and 2012. Even in the wake of the financial crisis of 2007-2008, the annual average pace of investments by private equity buyout firms in Europe has amounted to a full $0.27 \%$ of GDP (with investments being above $0.9 \%$ of GDP in the UK and $0.55 \%$ of GDP in Sweden). ${ }^{1}$ Private equity firms are thus becoming increasingly important in many markets.

A defining characteristic of private equity firms is that they are temporary owners of assets. The funds they raise to obtain capital to acquire firms have a limited time span after which they must be dissolved. This means that the median holding period of a company by a private equity firm is only around six years (Kaplan and Strömberg, 2009). Because private equity firms are forced to sell the companies they buy, the payoff from accounting for strategic product market effects when the time comes to resell the firms they have acquired can potentially be large. Kovenock and Phillips (1995) find evidence that firms with low productivity in concentrated markets are more likely to be acquired by a private equity firm and Hsu, Reed, and Rocholl (2010) present evidence that rivals to private equity backed firms experience decreases in profits following the acquisition. ${ }^{2}$

Yet, despite the spread of the private equity ownership form, there is little theoretical work on the effects of temporary ownership on competition, industry structure and total welfare in oligopolistic markets. In this paper, we develop such a theory by developing an auction-investment-auction oligopoly model. One firm (the target) has assets in need of restructuring and puts itself up for sale. Rival incumbents (permanent owners) and private equity firms (temporary owners) bid for the target. Postacquisition, if the target's assets are sold, the new owner implements a governance structure to induce a manager to restructure the target. If the owner is a private equity firm, the target is put up for sale after being restructured. The bidders are rival incumbents, but the private equity firm also has the option of placing the restructured target on the market as a separate entity by undertaking an initial public offering (IPO).

Our model underscores three properties of temporary ownership. First, temporary ownership leads to overinvestment relative to permanent ownership because temporary owners maximize the trade sale price net of restructuring costs from the resale auction rather than simply product market profits net of restructuring costs. The equilibrium resale price consists of an incumbent's product market profits from owning the target relative to the profits if the target is obtained by a rival incumbent. The equilibrium resale price increases more as a result of investments in governance and restructuring than product market profits do. Hence, temporary owners implement stronger governance structures and undertake more restructuring compared to permanent owners. This provides a novel demand side explanation for why empirical studies have consistently found that private equity backed firms are more productive, have managers with more intense compensation contracts, are more leveraged, and why leverage returns to normal after the resale. ${ }^{3}$

In terms of welfare, we show that overinvestment is beneficial for consumers as prices fall but that it hurts rival firms who see their margins deteriorate. When private equity firms acquire targets in need of substantial restructuring (such that the ex-post market share or price-cost margin is relatively low), the negative effect on rivals outweighs the positive effects on consumer surplus and total surplus declines.

\footnotetext{
${ }^{1}$ Statistics from the European Venture Capital Association pan European report for 2012. Available at http://evca.eu/. Accessed June 2013.

${ }^{2}$ Moreover, studying retail markets, Chevalier (1995a) and Chevalier (1995b) show that buyouts lead to softer product market competition in the industry if rivals are highly leveraged but that product market competition intensifies when rivals are less leveraged (suggesting that less leveraged rivals can afford to prey on highly leveraged buyout targets to force them to exit the industry).

${ }^{3}$ On productivity, see Amess (2003), Harris, Siegel, and Wright (2005) and Davis, Haltiwanger, Jarmin, Lerner, and Miranda (2009). On compensation and leverage, see Kaplan (1989), Leslie and Oyer (2009) and Axelson, Jenkinson, Strömberg, and Weisbach (2010).
} 
But when private equity firms acquire good targets and make them great (such that the ex-post market share or price-cost margin is relatively high), the consumer surplus effect outweighs the negative effect on rivals and total surplus increases. Intuitively, the negative effect on total surplus is greater when the ex-post market share or price-cost margin is lower because then the private equity backed firm steals profits from more efficient rivals, while when the ex-post market share or price-cost margin is higher the private equity backed firm steals profits from less efficient rivals. This effect is reminiscent of what goes on in Mankiw and Whinston (1986). They point out that if entry into an industry causes incumbents to reduce output, then entry can be privately but not socially optimal. In our setting, it is investment in governance and restructuring that can be privately but not socially optimal because of its effects on rivals in the industry. Other settings in which total surplus is likely to increase includes more concentrated markets (there are less rivals to steal profits from) and where there exist substantial opportunities for improving governance and undertaking restructuring (i.e. when the costs of these improvements are relatively low which implies that the ex-post market share or price-cost margin will be high).

The second property we underscore is that temporary owners can aid antitrust authorities in maximizing consumer surplus. ${ }^{4}$ In the presence of a sufficiently foresighted antitrust authority, the development of an active private equity market is beneficial to consumers for two reasons (in addition to the overinvestment effect). The first reason is that an active private equity market can trigger mergers in a merger stable industry. As pointed out by Salant, Switzer, and Reynolds (1983), consumer surplus enhancing or welfare enhancing mergers in an oligopoly may not be privately profitable which presents antitrust authorities with a problem since they cannot force firms to merge. We show that introducing private equity firms as bidders in the first acquisition auction changes the bidding behavior of incumbents because they now have incentives to outbid private equity firms to prevent overinvestment. Thus, the mere threat of a buyout acts as a trigger for previously privately unprofitable mergers. If an antitrust authority can prevent mergers that reduce consumer surplus, all mergers triggered by an active private equity market are beneficial for consumers. The second mechanism by which an active private equity market can benefit consumers is by preventing concentration in the industry. An antitrust authority may want to block an incumbent acquisition in the initial acquisition auction because of concerns of increasing concentration in the industry. But blocking acquisitions comes at the cost of forgoing governance improvements and restructuring in the target. In the presence of an active private equity market, the antitrust authority can instead allow a private equity buyout and ensure that the resale auction leads to an IPO by blocking trade sales. This prevents concentration in the industry while still ensuring that the target's assets are restructured. But because overinvestment incentives are weaker under IPOs than under trade sales, blocking trade sales is desirable only if preserving competition is more beneficial to consumers than overinvestment.

The third property of temporary ownership we underscore is that temporary ownership drives incentives for specialization in restructuring. By spreading costs of specializing in restructuring over multiple markets, private equity firms have stronger incentives than incumbents to invest in acquiring restructuring skills. Specialized restructuring skills help private equity firms outbid incumbents wanting to preemptively acquire the target to prevent overinvestment in governance and restructuring, and ensures that an active private equity market emerges in equilibrium. Thus, the "institution" of temporary ownership solves the under provision of industrial reorganization in the market by allowing one actor to use its restructuring skill in several firms and several markets.

We have organized the paper as follows. The next section discusses our contribution to the literature. In section 3, we set up and solve the model by considering trade sales as the exit route and discuss the welfare implications of temporary ownership in section 4 . In section 5 , we discuss antitrust policy in the presence of temporary owners and in section 6 we discuss specialization in restructuring. We conclude in section 7. In appendix B, we generalize the model to allow for IPOs while appendix C contains several additional extensions of our basic set up.

\section{Contribution to the literature}

First, our paper contributes by introducing private equity firms to the industrial organization literature. The traditional literature on exogenous mergers has focused on how mergers affect prices, profits and

\footnotetext{
${ }^{4}$ Antitrust authorities often intervene in mergers and acquisitions involving private equity firms. For example, in October 2011 a federal judge in the US blocked H\&R Block from acquiring 2nd Story Software (owned by the private equity firm TA Associates). The Justice Department argued that the merger would harm competition in the market for digital tax preparation services which is dominated by only three players (H\&R Block, 2nd Story Software and Intuit). For more, see the New York Times Dealbook story at http://dealbook.nytimes.com/2011/11/01/judge-scuttles-hr-block-deal/.
} 
welfare but it has ignored the effects of owner asymmetries and pre/post merger investments. ${ }^{5}$ Recently, a literature on endogenous mergers has emerged in which the central question is who merges with whom. ${ }^{6}$ A part of this literature has studied pre-merger investments and auctions with externalities. ${ }^{7}$ Closest in spirit to our paper is Norbäck and Persson (2009), who develop an auction-investment-auction model with overinvestment aimed at studying how venture capital firms help entrepreneurs develop an innovation for a market. We extend their paper by allowing for resales to different owner types (incumbents or outsiders), by conducting a welfare analysis of temporary ownership, and by discussing optimal antitrust policy in the presence of temporary owners. ${ }^{8}$ Our discussion of antitrust policy in a setting with repeated mergers implies that our paper also relates to the literature on mergers and antitrust review in a dynamic context (see, for instance, Nilssen and Sorgard (1998), Motta and Vasconcelos (2005) and Nocke and Whinston (2010)). In particular, Nocke and Whinston (2010) show that if each firm in a Cournot setting is involved in, at most, one potential merger and if disapproved mergers can still take place later, then a completely myopic consumer surplus based approval policy maximizes discounted consumer surplus. These conditions are not fulfilled in our setting: firms can be involved in multiple potential mergers and, furthermore, heterogeneity in ownership type implies that objective functions of firms differ. It is thus essential that antitrust authorities are forward looking when it comes to antitrust policy in the presence of temporary owners. ${ }^{9}$

Second, our paper contributes to the finance literature on private equity firms. The seminal (informal) work on buyouts proposed that private equity firms are specialists at solving managerial agency problems, mainly through closer monitoring, extensive use of debt and giving the manager ownership in the firm (Jensen, 1986; and Jensen, 1989). By concentrating ownership, they solve free-rider problems related to dispersed ownership (Berle and Means, 1932; Jensen and Meckling, 1976). This literature has, however, not focused on temporary ownership, endogenous ownership, product market effects, antitrust policy or conducting welfare analyzes. There is also an emerging finance literature on the difference between strategic and financial buyers of assets in takeover auctions (e.g. Gorbenko and Malenko (2012), MartosVila, Rhodes-Kropf, and Harford (2012) and Hege, Lovo, Slovin, and Sushka (2012)). This literature has so far not accounted for the role of temporary ownership and product market effects in shaping difference in bidding and investment behavior between strategic and financial buyers.

Finally, we contribute to the literature on corporate finance and product markets. This literature has examined the interaction between corporate governance decisions, capital structure decisions, and product market actions and outcomes. Examples of mechanisms identified in this literature are that limited liability commits a leveraged firm to producing more output in the product market since shareholders care more about positive than negative states of the world (Brander and Lewis, 1986) and that firms with good access to financial markets have incentives to prey on financially weaker rivals to force them out of the market (Bolton and Scharfstein, 1990). ${ }^{10}$ Our paper adds to this literature by focusing on a situation in which financial intermediation (the structure of private equity funds) implies that corporate

\footnotetext{
${ }^{5}$ See, for example, Salant et al. (1983), Perry and Porter (1985), Deneckere and Davidson (1985), Farrell and Shapiro (1990), and Gilbert and Newbery (1992). Our paper also relates to the "exogenous merger" literature in finance showing that mergers can be triggered by changes in productivity and cost of capital (Jovanovic and Rousseau, 2002; and Maksimovic and Phillips, 2002).

${ }^{6}$ See, for instance, Kamien and Zang (1990), Gowrisankaran (1999), Horn and Persson (2001), and Fridolfsson and Stennek (2005).

${ }^{7}$ See, for instance, Norbäck and Persson (2008), Friberg, Norbäck, and Persson (2008), Fabrizi, Lippert, Norbäck, and Persson (2008), Norbäck, Persson, and Svensson (2011) and Norbäck, Persson, and Tåg (2011).

${ }^{8}$ In addition to extending the analysis in these directions, propositions one and two in this paper also generalize proposition one and four in Norbäck and Persson (2009) by extending them to account for how restructuring/investment incentives are affected through the governance structure of firms. This is important as it underscores that temporary ownership not only affects investment incentives but optimal governance structures of firms as well (which could partly explain why private equity firms tend to impose strict monitoring, take on more leverage, and give managers a large ownership stake in the firm).

${ }^{9}$ From a more theoretical perspective, our paper also relates to the literature on endogenous ownership and efficiency dating back to Coase (1960). He argued that in a zero-transaction world, laissez-faire always leads to optimal outcomes irrespective of the initial assignment of property rights. Departing from the zero transaction cost assumption, authors such as Grossman and Hart (1986) and Hart and Moore (1990), have shown that ownership structure has implications for efficiency when contracts are incomplete. In particular, Jehiel and Moldovanu (1999) shows that ownership allocation in a resale market is not efficient when auctions have externalities and contracts are incomplete. We contribute to this literature by examining the outcome in a resale market in which investments take place prior to resale. This enables us to show that owners buying firms for resale have incentives to overinvest in relation to the eventual acquirers first best as a result of the externalities in the resale auction. Hence, not only can the ownership allocation be distorted but investments can be distorted as well. The overinvestment effect is also present in Katz and Shapiro (1986), who study the optimal licensing fee of a research lab which can affect the size of the innovation, but in their paper the ownership structure is not determined.

${ }^{10}$ See also Banal-Estanol and Ottaviani (2006) for mergers with product market risk; Maksimovic (1988) and Gilo, Moshe, and Spiegel (2006) for tacit collusion; and Brander and Lewis (1988) on bankruptcy costs.
} 
Figure 1: The timing of the game.

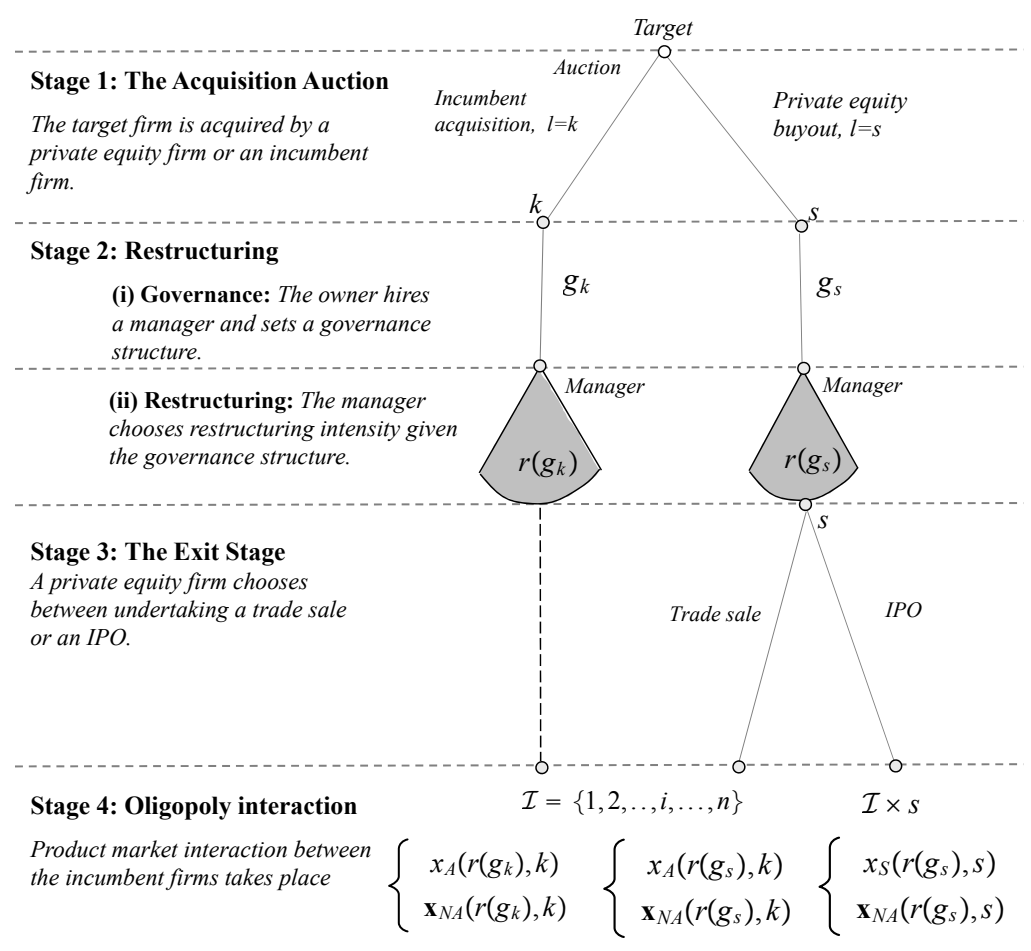

Notes. This figure illustrates and describes the four stage game we analyze: the initial acquisition auction, the restructuring and governance structure stage, the exit auction, and oligopoly product market interaction.

ownership is temporary. We show that a commitment to temporary ownership when product markets are oligopolistic gives strong incentives to implement tight corporate governance structures and provides incentives for using higher leverage.

\section{The Model}

\subsection{Setup}

We consider an oligopoly industry served by a set $\mathcal{I}=\{1,2, . ., i, \ldots, n\}$ of symmetric incumbents, each possessing the basic assets necessary for production. The industry also contains a target firm. The target's industry specific assets are in need of restructuring, but the target cannot undertake the restructuring process by itself because of lack of cash or knowledge. The game is illustrated in Figure 1 and proceeds as follows.

In stage one, an acquisition of the target by incumbent $i$ or by the private equity firm $j \in \mathcal{J}=$ $\{1,2, . ., j, . ., m\}$ takes place at the acquisition price $S^{1}$, determined in a first-price perfect information auction. ${ }^{11}$ Due to the symmetry with firm types, the new owner of the target firm, $l$, is either an incumbent buying to keep $(l=k)$ or a private equity firm buying to sell $(l=s)$.

In stage two, the new owner hires a manager to restructure the target. The new owner must provide incentives for the manager to exert effort and implements a governance structure of intensity $g_{l}$. The manager then determines the amount of restructuring $r\left(g_{l}\right)$ to be undertaken.

In stage three, if the target was bought by a private equity firm, the private equity firm arranges a first price perfect information auction to sell the restructured target. The bidders are the rival incumbents in the industry. We term the exit a trade sale if a rival incumbent wins the auction and an IPO if the firm is bought by an outsider to the industry. To underscore the main mechanism, we start the analysis in this section by assuming that only exit by trade sale is possible. We then generalize the model to include IPOs in appendix B. ${ }^{12}$

\footnotetext{
${ }^{11}$ We discuss other potential selling mechanisms in appendix C.

${ }^{12}$ Kaplan and Strömberg (2009) report that $38 \%$ of all realized exits world-wide are trade sales and $14 \%$ are IPOs.
} 
In stage four, incumbents compete in the product market by setting price or quantity $\left(x_{i}\right)$ given restructuring $\left(r\left(g_{l}\right)\right)$ and the identity of the firm who owns the restructured target.

\subsection{Stage 4: Product Market Interaction}

Using backward induction, we start in stage four with product market competition between the $n$ incumbents. One of them owns the restructured target. Since product market competition takes place post-exit, private equity firms do not own assets in this stage and hence do not produce.

Using the ex-ante symmetry among incumbents, we distinguish between two firm types $h$ : the acquiring incumbent $(h=A)$ and the non-acquiring incumbents $(h=N A)$. An incumbent of type $h=\{A, N A\}$ chooses an action $x_{h} \in R^{+}$to maximize the direct product market profit $\Pi_{h}\left(x_{h}, \mathbf{x}_{-h}, r\right)$. The profit depends on its own actions $x_{h}$; its rivals' actions $\mathbf{x}_{-h}$ (an $(N-1) \times 1$ vector); how much the target has been restructured $(r)$; and whether the incumbent is an acquirer $(h=A)$ or a non-acquirer $(h=N A)$. We assume that a unique Nash-Equilibrium in actions, $\mathbf{x}^{*}(r)$, exists and that it is defined from the first-order conditions

$$
\frac{\partial \Pi_{A}}{\partial x_{A}}\left(x_{A}^{*}(r), x_{-A}^{*}(r), r\right)=0, \quad \frac{\partial \Pi_{N A}}{\partial x_{N A}}\left(x_{N A}^{*}(r), x_{-N A}^{*}(r), r\right)=0 .
$$

We can then define the reduced-form product market profits of the acquirer and a non-acquirer as direct functions of the level of restructuring $r: R_{A}(r) \equiv \Pi_{A}\left(x_{A}^{*}(r), x_{-A}^{*}(r), r\right)$ and $R_{N A}(r) \equiv \Pi_{N A}\left(x_{N A}^{*}(r), x_{-N A}^{*}(r), r\right)$. We make the assumption that restructuring increases the profits of the acquirer, but reduces the profits for non-acquiring incumbents as they must compete with a better rival.

Assumption 1. $\frac{d R_{A}}{d r}>0$ and $\frac{d R_{N A}}{d r}<0$.

Our notion of restructuring is based on private equity firms implementing governance, financial and operational improvements to restructure the target. ${ }^{13}$ The empirical literature based on deals in the 1980s has suggested that private equity firms to a large extent purchase under-performing firms with entrenched managers, too high capital expenditures, and over-diversified business lines. However, more recent evidence suggests that private equity firms today are more oriented towards operational improvements and helping firms grow. ${ }^{14}$ Our formalization of restructuring says that the profitability of the target increases in restructuring, and that rivals' profits decrease in restructuring, which is compatible with both restructuring underperforming firms and helping capital-starved firms grow. However, our model does not cover instances in which the growth of the target firm involves the development of such new innovative products that demand expansion effects dominate the negative effect on rivals (violating assumption 1). Moreover, some private equity transaction might simply take place because of opportunities to restructure the balance sheet (using tax and financial engineering). We will later in the model introduce an fixed cost restructuring advantage for private equity firms which could include financial and tax advantages private equity firms have. If there are no effects on rivals from these activities, the effects on governance and restructuring we emphasize will be absent.

Assumption 1 is compatible with several oligopoly models. One is the Linear Cournot model.

Example 1. The Linear Cournot Model. The oligopoly interaction is Cournot competition with homogenous goods. The product market profit is $\Pi_{i}=\left(P-c_{i}\right) q_{i}$ where firms face inverse demand $P=a-Q$, where $a>0$ is a demand parameter and $Q=\sum_{i=1}^{n} q_{i}$ is aggregate output. Acquiring the restructured target reduces the marginal cost. Making a distinction between firm types, we have:

$$
c_{A}=c-\gamma r, \quad c_{N A}=c .
$$

The parameter $\gamma>0$ measures how effective restructuring is. Equation (1) take the form $\partial \Pi_{h} / \partial q_{h}=$ $P-c_{h}-q_{h}=0$ for $h=\{A, N A\}$, which can be solved for optimal quantities $\mathbf{q}^{*}=\left(q_{h}^{*}, q_{-h}^{*}\right)$. Here $q_{h}^{*}$ is the output of a firm of type $h$ and $q_{-h}^{*}$ is the output of its competitors. Reduced-form profits are $R_{h}=\left[q_{h}^{*}\right]^{2}$ since $\partial \Pi_{h} / \partial q_{h}=0$ implies $P-c_{h}=q_{h}^{*}$. The equilibrium outputs are $q_{A}^{*}=(a-c+n \gamma r) /(n+1)$ and $q_{N A}^{*}=(a-c-\gamma r) /(n+1)$, which satisfies $d R_{A} / d r>0$ and $d R_{N A} / d r<0$.

Assumption 1 is also compatible with many other oligopoly models with other competitive modes, cost and demand structures, such as Bertrand models with differentiated products and multi-plant models as long as restructuring either affects the variable production cost or the quality of the product sold by the acquiring incumbent. To demonstrate this, we in appendix $\mathrm{C}$ show that Assumption 1 is fulfilled for

\footnotetext{
${ }^{13}$ See Jensen (1989) or Kaplan and Strömberg (2009).

${ }^{14}$ See, for instance, Boucly, Sraer, and Thesmar (2011), Olsson and Tåg (2012) or Kaplan and Strömberg (2009).
} 
many parameter values in the differentiated product multi-plant model where the acquiring incumbent and the target firm hold different varieties of the good or service. ${ }^{15}$

\subsection{Stage 3: The Exit Auction}

If a buyout takes place in stage one, the private equity firm exits its investment through a first price perfect information auction with externalities in stage three. ${ }^{16}$ The $n$ incumbents simultaneously post bids, which are accepted or rejected by the private equity firm. Each incumbent announces a bid $b_{i}$, with $\mathbf{b}=\left(b_{1}, \ldots, b_{i}, \ldots b_{n}\right) \in R^{n}$ being the vector of these bids. Following the announcement of $\mathbf{b}$, the restructured target is sold to the incumbent with the highest bid. The acquisition is solved for Nash equilibria in undominated pure strategies. There is a smallest amount $\epsilon$ chosen such that all inequalities are preserved if $\epsilon$ is added or subtracted (to avoid the problem that an equilibrium in pure strategies does not exist). If more than one firm makes an offer of the highest value, each such incumbent obtains the target with equal probability.

The exit auction is solved for Nash equilibria in undominated pure strategies. An incumbent's maximum willingness to pay for the target is

$$
\omega_{k k}=R_{A}(r)-R_{N A}(r) .
$$

The first term shows the profit for the incumbent if it obtains the target. The second term shows the profit of the same incumbent if it does not obtain the target and is forced to compete with a rival that obtained the target. Denoting the equilibrium trade sale price as $S^{3}(r)$, Lemma 1 follows.

Lemma 1. The equilibrium trade sale price is $S^{3}(r)=R_{A}(r)-R_{N A}(r)$.

Proof. See appendix A.

Intuitively, the incumbents are ex-ante symmetric so they will all post the same bid equal to their maximum valuation $\omega_{k k}$.

\subsection{Stage 2: Governance and Restructuring}

In stage two, the new owner hires a manager to restructure the target. The new owners (an incumbent or a private equity firm) decide on a governance structure $g$ defined as a measure implemented by the owners to induce more restructuring efforts by the manager. More specifically, in a first period of stage two the new owner hires a manager and sets a governance structure. Given the governance structure, the manager restructures the target in the second period of stage two. We solve stage two by backward induction.

Consider first restructuring by the manager given the governance structure. Let the utility of the manager be $U(r, g)=w(r, g)-e(r)$, where $w(r, g)$ is the benefit to the manager from doing more restructuring with $w_{r}^{\prime}>0$. The effort cost (or private benefit loss) from restructuring for the manager is represented by $e(r)$, with $e^{\prime}>0$ and $e^{\prime \prime}>0$. For a given governance structure $g$, the optimal restructuring by the manager is $r^{*}(g)=\arg \max _{r} U(r, g)=w(r, g)-e(r)$, with associated first order condition

$$
w_{r}^{\prime}=e\left(r^{*}(g)\right)
$$

Assuming that $U(r, g)$ is strictly concave in $g$, and that better governance increases the managers marginal pay-off of restructuring $\left(w_{r g}^{\prime \prime}>0\right)$, better governance increases restructuring efforts. This follows from differentiating the first-order condition in equation (4) to obtain

$$
\frac{d r^{*}}{d g}=-\frac{w_{r g}^{\prime \prime}}{w_{r r}^{\prime \prime}-e_{r r}^{\prime \prime}}>0 .
$$

The optimal restructuring as a function of the governance structure is illustrated in Figure 2(i). To proceed, it is useful to define reduced-form profit functions $R_{A}(g) \equiv R_{A}\left(r^{*}(g)\right)$ and $R_{N A}(g) \equiv R_{N A}\left(r^{*}(g)\right)$, and the reduced-form utility for the managers as $U(g)=w\left(r^{*}(g), g\right)-e\left(r^{*}(g)\right)$.

\footnotetext{
${ }^{15}$ Intuitively, what we need to be concerned about is that an incumbent could be so efficient at producing its own product that an increase in restructuring of the target's product will cannibalize on profitable sales in the incumbent's original plant. Aggregate profits could then be reduced and Assumption 1 would no longer hold.

${ }^{16}$ For more on these auctions, see Jehiel and Moldovanu (1999), Jehiel et al. (1999) or Jehiel and Moldovanu (2000).
} 
Figure 2: Optimal governance, restructuring and ownership.

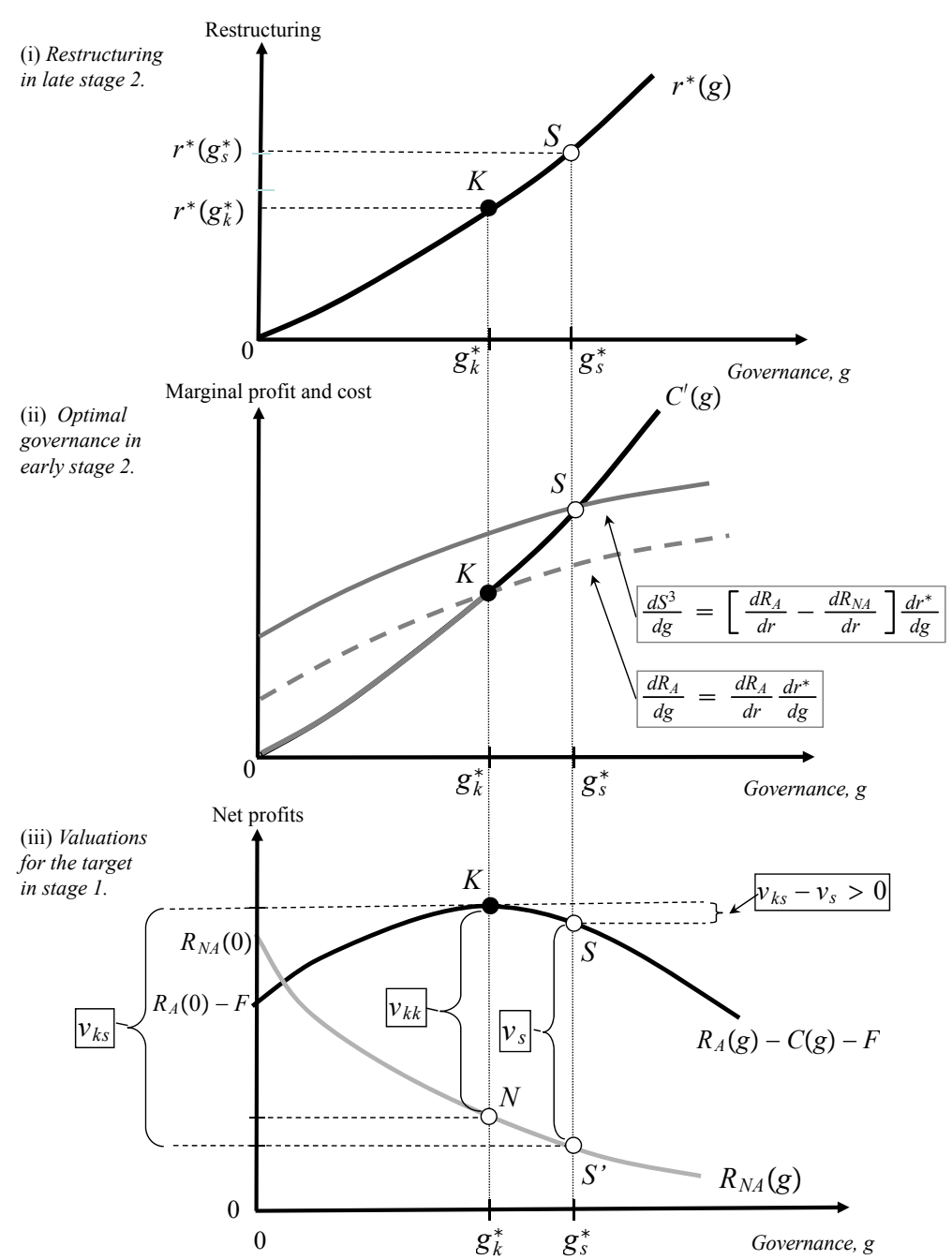

Notes. Part (i) of this figure illustrates that restructuring intensity $r$ increases with governance $g$. Part (ii) illustrates how temporary owners maximizing the trade sale price sets governance higher than permanent owners maximizing product market profits $\left(g_{s}^{*}>g_{k}^{*}\right)$. Part (iii) illustrates how the valuations of incumbents and private equity firms depend on governance intensity ignoring the fixed cost advantage $\Delta$. In equilibrium, $v_{k s}>v_{s}$ so a private equity buyout cannot take place because incumbents have incentives to prevent the buyout.

Next, we solve for the optimal governance structure. Restructuring is associated with two types of costs for the owners: variable restructuring costs are $k(r)$, with $k^{\prime}(r)>0$ and the cost of imposing a governance structure are $c(g)$ with $c^{\prime}(g)>0 .{ }^{17}$ Define total variable restructuring costs as a reducedfunction of $g$ as $C(g)=k\left(r^{*}(g)\right)+c(g)$, with $d C / d g=(d k / d r)\left(d r^{*} / d g\right)+c^{\prime}(g)>0$ (which we denote by $C^{\prime}(g)$ for simplicity) and $d^{2} C / d g^{2}>0$. Fixed restructuring costs for incumbents are $F$. Private equity firms have a fixed restructuring cost of $F-\Delta$ with a potential advantage equal to $\Delta \geq 0$. In section 6 we endogenize $\Delta$ by allowing both private equity firms and incumbents to invest in reducing fixed costs from $F$ to $F-\Delta$.

Suppose first an incumbent obtained the target in stage one. The incumbent will maximize net profits by choosing the governance structure $g_{k}$ optimally: $g_{k}^{*}=\arg \max _{g}\left[R_{A}(g)-C(g)-F\right]$ with the associated first-order condition

$$
\frac{d R_{A}}{d g}=\frac{d R_{A}}{d r} \frac{d r^{*}}{d g}=C^{\prime}\left(g_{k}^{*}\right) .
$$

\footnotetext{
${ }^{17}$ At the end of this subsection, we give explicit examples of $c(g)$ : the cost $c(g)$ can be the wage costs of the manager $(c(g)$ equals $w(r, g))$, it could be monitoring costs imposed on the firm, or it could be costs associated with greater leverage (if leverage induces the manager to work harder).
} 
The optimal governance structure $g_{k}^{*}$ is shown at point $K$ in Figure 2(ii). The marginal revenue is $\left(d R_{A} / d r\right)\left(d r^{*} / d g\right)$, consisting of the marginal increase in restructuring from better governance $\left(d r^{*} / d g>\right.$ $0)$ and the marginal effect of restructuring on profits $\left(d R_{A} / d r>0\right)$. The marginal cost is $C^{\prime}=$ $(d k / d r)\left(d r^{*} / d g\right)+c^{\prime}(g)$, consisting of the marginal increase in restructuring costs $(d k / d r)\left(d r^{*} / d g\right)$ and the marginal increase in costs of governance $\left(c^{\prime}(g)\right)$.

Suppose now that a private equity firm obtained the target in stage one. The private equity firm will maximize the equilibrium trade sale price by choosing the governance structure $g_{s}$ optimally: $g_{s}^{*}=$ $\arg \max _{g}\left[S^{3}-C(g)-(F-\Delta)\right]$ with $S^{3}=R_{A}(g)-R_{N A}(g)$. The associated first-order condition is

$$
\frac{d S^{3}}{d g}=\left[\frac{d R_{A}}{d r}-\frac{d R_{N A}}{d r}\right] \frac{d r^{*}}{d g}=C^{\prime}\left(g_{s}^{*}\right) .
$$

The optimal governance structure $g_{s}^{*}$ is shown point $S$ in Figure 2(ii). Compare the first order conditions in equations (6) and (7). Both types of firms have the same marginal cost $\left(C^{\prime}\right)$. However, the marginal revenue is not the same. An incumbent accounts for how governance affects product market profits $\left(\left(d R_{A} / d r\right)\left(d r^{*} / d g\right)>0\right)$, while a private equity firm accounts for how governance affects the trade sale price. The trade sale price increases both because product market profits increase $\left(\left(d R_{A} / d r\right)\left(d r^{*} / d g\right)>\right.$ $0)$, and because product market profits of non-acquiring incumbents decrease $\left(\left(d R_{N A} / d r\right)\left(d r^{*} / d g\right)<0\right)$. This is illustrated in Figure 2(ii) by the marginal revenue curve of a private equity firm lying above an incumbents marginal revenue curve. In Figure 2(ii) the location of point $S$ is to the right of point $K$. Since better governance translates into increased restructuring efforts, managers in private equity backed firms do more restructuring $\left(r^{*}\left(g_{s}^{*}\right)>r^{*}\left(g_{k}^{*}\right)\right)$ which is illustrated in Figure 2(i).

Proposition 1. Private equity backed firms use stronger governance structures than incumbents $\left(g_{s}^{*}>\right.$ $\left.g_{k}^{*}\right)$ and subsequently are more intensively restructured $\left(r^{*}\left(g_{s}^{*}\right)>r^{*}\left(g_{k}^{*}\right)\right)$.

The governance structure could take many forms, but most relevant for private equity firms is managerial ownership, debt, and monitoring. In the following examples, we assume that the private effort of the manager $e(r)$ and the restructuring cost $k(r)$ for the firm are increasing convex functions.

Example 2. Managerial ownership. The utility of the manager is $U(r, g)=w(r, g)-e(r)$ where $g$ is a share of ownership in the firm for a manager. Then, the payment to the manager is $w(r, g)=$ $g\left[R_{A}(r)-k(r)-F\right]$. Since equation (4) takes the form $g\left[r^{*}(g)\left(d R_{A} / d r\right)-k^{\prime}\right]=e\left(r^{*}(g)\right)$, we have $w_{r}^{\prime}=g\left[r\left(d R_{A} / d r\right)-k^{\prime}(r)\right]>0$ and $w_{r g}^{\prime \prime}=r\left(d R_{A} / d r\right)+k^{\prime}(r)>0$. Hence, from equation $(5), d r^{*} / d g>$ 0 . The cost for the firm is $C(g)=k\left(r^{*}(g)\right)+c(g)$, where $c(g)=g\left[R_{A}\left(r^{*}(g)\right)-k\left(r^{*}(g)\right)-F\right]$ with $d c(g) / d g=R_{A}\left(r^{*}(g)\right)-k\left(r^{*}(g)\right)-F+g\left[r^{*}(g)\left(d R_{A} / d r\right)+k^{\prime}\right]\left(d r^{*} / d g\right)>0$. Hence, $C^{\prime}(g)>0$ and from equations (6) and (7) we have $g_{s}^{*}>g_{k}^{*}$ and $r^{*}\left(g_{s}^{*}\right)>r^{*}\left(g_{k}^{*}\right)$.

Example 3. Debt. Suppose that the manager receives a fixed wage of $b$ but is sacked if the firm runs into financial trouble: $w(r, g)=\rho(r, g) b$, with $\rho(r, g)$ being the probability of default with $\frac{d \rho}{d r}<0$. Then, $w_{r}^{\prime}=b \frac{d \rho}{d r}<0 w_{r g}^{\prime \prime}=\rho_{r g}^{\prime \prime}(r, g) b>0$ if increased debt levels makes the probability of default more sensitive to restructuring efforts. The cost of financial distress is $c(g)$ with $d c(g) / d g>0$. From equations (6) and (7) we have $g_{s}^{*}>g_{k}^{*}$ and $r^{*}\left(g_{s}^{*}\right)>r^{*}\left(g_{k}^{*}\right)$.

Example 4. Monitoring. Suppose that the manager receives a fixed wage of $b$ but is sacked if he or she is found shirking: $w(r, g)=\rho(r, g) b$, with $\rho(r, g)$ being the probability of being detected shirking with $\frac{d \rho}{d r}>0$. Then $w_{r g}^{\prime \prime}=\rho_{r g}^{\prime \prime}(r, g) b>0$ if increased monitoring makes the probability of being detected more sensitive to restructuring efforts. The cost of monitoring is $c(g)$ with $d c(g) / d g>0$. From equations (6) and (7) we have $g_{s}^{*}>g_{k}^{*}$ and $r^{*}\left(g_{s}^{*}\right)>r^{*}\left(g_{k}^{*}\right)$.

These examples are consistent with empirical evidence that private equity backed firms have higher managerial ownership, higher leverage and are more productive. ${ }^{18}$ Our model also predicts that leverage will decrease once the private equity firm has exited their investment. In addition to these examples, we show in appendix $\mathrm{C}$ that our general specification includes governance structures such that (i) private equity backed firms offer managers a share of the trade sale price; (ii) managerial ownership is combined with a fixed wage for the manager; and (iii) there are exogenous cost advantages for private equity firms in variable restructuring costs.

\footnotetext{
${ }^{18}$ For managerial ownership, see Kaplan (1989), Leslie and Oyer (2009) and Acharya and Kehoe (2008); for leverage see Axelson et al. (2010) and Leslie and Oyer (2009); and for productivity see Lichtenberg and Siegel (1990); Amess (2003); Harris et al. (2005) and Davis et al. (2009).
} 


\subsection{Stage 1: The Acquisition Auction}

The acquisition auction in stage one is a first price perfect information auction with externalities. We solve for Nash equilibria in undominated pure strategies. The $n$ incumbents and the $m$ private equity firms simultaneously post bids, which are accepted or rejected by the target. ${ }^{19}$ Each incumbent and private equity firm announces a bid $b_{i}$, with $\mathbf{b}=\left(b_{1}, \ldots, b_{i}, \ldots b_{n+m}\right) \in R^{n+m}$ is the vector of these bids. Following the announcement of $\mathbf{b}$, the target is sold to the incumbent or the private equity firm with the highest bid. If more than one firm makes an offer of the highest value, each such bidder obtains the target with equal probability.

Since the auction has externalities, the maximum valuations are determined as profits from winning the auction in relation to profits from losing it. We define the valuations $v_{s}, v_{k k}$ and $v_{k s}$ as follows.

- $v_{s}$ is the valuation of obtaining the target for a private equity firm. Evaluate the profit for a private equity firm at $g_{s}^{*}$ to obtain

$$
v_{s}=\underbrace{R_{A}\left(g_{s}^{*}\right)-R_{N A}\left(g_{s}^{*}\right)}_{\text {Trade sale price } S^{3^{*}}\left(g_{s}^{*}\right)}-C\left(g_{s}^{*}\right)-(F-\Delta) .
$$

- $v_{k k}$ is an incumbent's valuation of obtaining the target if another incumbent would otherwise have obtained it. Evaluating the profit of an acquiring incumbent and the profit for a non-acquiring incumbent at $g_{k}^{*}$, we obtain

$$
v_{k k}=\underbrace{R_{A}\left(g_{k}^{*}\right)-C\left(g_{k}^{*}\right)-F}_{\text {Acquire and restructure. }}-\underbrace{R_{N A}\left(g_{k}^{*}\right)}_{\text {A rival makes the acquisition. }} .
$$

- $v_{k s}$ is an incumbent's valuation of obtaining the target if a private equity firm would otherwise have obtained it, restructured it, and sold it back to the industry. Evaluating the profit of an incumbent at $g_{k}^{*}$ and the profit for an non-acquiring incumbent at $g_{s}^{*}$, we obtain

$$
v_{k s}=\underbrace{R_{A}\left(g_{k}^{*}\right)-C\left(g_{k}^{*}\right)-F}_{\text {Acquire and restructure. }}-\underbrace{R_{N A}\left(g_{s}^{*}\right)}_{\text {A buyout occurs. }} .
$$

Given equations (8), (9) and (10), we derive the following Proposition.

Proposition 2. In a pure strategy Nash-equilibrium, private equity firms need a sufficiently large fixed restructuring cost advantage $\Delta$ to outbid incumbents. Let $\bar{\Delta} \equiv R_{A}\left(g_{k}^{*}\right)-C\left(g_{k}^{*}\right)-\left[R_{A}\left(g_{s}^{*}\right)-C\left(g_{s}^{*}\right)\right]>0$. For $\Delta<\bar{\Delta}$ the target is acquired by an incumbent at price $S^{1 *}=v_{s}$. For $\Delta>\bar{\Delta}$ a buyout occurs at price $S^{1^{*}}=v_{s}$.

To prove Proposition 2 let us first establish a ranking between firms' valuations in equations (8)(10). First, a private equity firm must have a higher valuation than an incumbent preempting a rival acquisition: $v_{s}>v_{k k}$. This follows since a private equity firm sets $g$ to maximize incumbents willingness to pay net of restructuring costs, $g_{s}^{*}=\arg \max _{g}\left[S^{3^{*}}-C(g)-(F-\Delta)\right]=\arg \max _{g}\left[R_{A}(g)-R_{N A}(g)-\right.$ $C(g)-(F-\Delta)]$. Second, an incumbent preempting a private equity buyout must have a higher valuation than an incumbent preempting a rival acquisition: $v_{k s}>v_{k k}$. This holds because $v_{k s}-v_{k k}=R_{N A}\left(g_{k}^{*}\right)-$ $R_{N A}\left(g_{s}^{*}\right)>0$ since $g_{s}^{*}>g_{k}^{*}$. This tells us that firms' valuations fulfill

$$
\min \left\{v_{s}, v_{k s}\right\}>v_{k k} .
$$

Let us now show that the acquisition price must be $S^{1^{*}}=v_{s}$. Since multiple symmetric private equity firms bid for the target, the acquisition price $S^{1^{*}}$ must be at least $v_{s}$. Incumbents will not bid higher than $v_{s}$. If an incumbent believes that a rival will bid $v_{s}$, it has no incentive to bid higher since from equation (11) the value of preempting a rival is lower than the value of preempting a private equity firm $\left(v_{k k}<v_{s}\right)$.

Which type of firm will buy the target? Compare the net profit of an incumbent that buys the target directly in stage one at price $v_{s}\left(\pi_{A}^{1}=R_{A}\left(g_{k}^{*}\right)-C\left(g_{k}^{*}\right)-F-v_{s}\right)$ to the net profit of the incumbent

\footnotetext{
${ }^{19}$ In this section, we assume that the target firm has a reservation price of $v_{t}=0$. We relax this assumption in Section 5 .
} 
when buying a restructured target late in stage three from a private equity firm $\left(\pi_{A}^{3}=R_{N A}\left(g_{k}^{*}\right)-S^{3^{*}}=\right.$ $\left.R_{N A}\left(g_{s}^{*}\right)\right)$. We obtain

$$
\begin{aligned}
\pi_{A}^{1}-\pi_{A}^{3} & =R_{A}\left(g_{k}^{*}\right)-C\left(g_{k}^{*}\right)-F-\underbrace{\left[S^{3^{*}}-C\left(g_{s}^{*}\right)-(F-\Delta)\right]}_{S^{1^{*}}=v_{s}}-[\underbrace{\left.R_{A}\left(g_{k}^{*}\right)-S^{3^{*}}\right]}_{\pi_{A}^{3}=R_{N A}\left(g_{s}^{*}\right)} \\
& =\underbrace{\left[R_{A}\left(g_{k}^{*}\right)-C\left(g_{k}^{*}\right)\right]-\left[R_{A}\left(g_{s}^{*}\right)-C\left(g_{s}^{*}\right)\right]}_{\bar{\Delta}>0}-\Delta \\
& =v_{k s}-v_{s},
\end{aligned}
$$

where $\bar{\Delta} \equiv R_{A}\left(g_{k}^{*}\right)-C\left(g_{k}^{*}\right)-\left[R_{A}\left(g_{s}^{*}\right)-C\left(g_{s}^{*}\right)\right]>0$ since $g_{k}^{*}=\arg \max _{g}\left[R_{A}(g)-C(g)\right]$, and where $\pi_{A}^{3}=R_{A}\left(g_{k}^{*}\right)-\left(R_{A}\left(g_{k}^{*}\right)-R_{N A}\left(g_{k}^{*}\right)\right)$ is the net profit for the acquirer when acquiring late.

As shown by the first row of equation (12), an incumbent will pay the trade sale price $S^{3^{*}}$, either in the bidding competition in stage one with private equity firms or in the exit stage with rival incumbents. As revealed by the first term of the second row, a direct acquisition is then driven by the incentive to avoid costly overinvestment in restructuring (induced by overly strong governance structures from an incumbents perspective). Indeed, without an advantage in restructuring a buyout cannot occur. This is shown in Figure 2(iii), where $v_{k s}-v_{s}>0$. Only if the excessive investments are compensated for by a lower fixed restructuring $\operatorname{cost}(\Delta>\bar{\Delta}>0)$ will a private equity firm be able to obtain the target (we close the model by endogenizing $\Delta$ in section 6). Note that in the equilibrium in which an incumbent acquires the target firm, only the acquirer bids an amount above the private equity firms' bids, $v_{s}$. However, the analysis does not predict which incumbent will be selected to outbid the private equity firms: the gains from a direct preemptive acquisition by an incumbent in stage one are unevenly distributed among incumbents. A coordination failure among incumbents can then occur as $v_{k s}>v_{s}>v_{k k}$. The acquiring incumbent bears the cost of the acquisition, while the other incumbents can free-ride:

$$
\underbrace{R_{N A}\left(g_{k}^{*}\right)}_{\text {Non-acquiring incumbent. }}>\underbrace{\pi_{A}^{1}=R_{A}\left(g_{k}^{*}\right)-C\left(g_{k}^{*}\right)-F-v_{s}}_{\text {Acquiring incumbent paying } S^{1^{*}}=v_{s} .}>\underbrace{R_{N A}\left(g_{s}^{*}\right)}_{\text {Incumbent if a buyout occurs. }} .
$$

Under a coordination failure between incumbents, private equity firms can outbid the incumbents even though $v_{k s}>v_{s}$ and private equity firms have no advantages at restructuring $(\Delta=0)$. If we assume that private equity firms no advantages at restructuring $(\Delta=0)$, then there exists a mixed strategy equilibrium in which incumbents bid $v_{s}$ with some probability, and private equity firms always bid their maximum valuation $v_{s}$. This can formally be shown by extending the auction in stage one to mixed strategy equilibria. In a mixed strategy equilibrium, incumbents can bid $v_{s}$ with some probability, whereas private equity firms always bid their maximum valuation $v_{s}$. There are two possible outcomes: at least one incumbent bid $v_{s}$ and a preemptive acquisition takes place, or no incumbents bid for the target and a private equity firm obtains it at price $v_{s}$.

We end this section with two remarks.

Remark 1 (Incumbents buying to sell). Would our results still hold if incumbents could imitate private equity firms and also buy to sell? Suppose that an incumbent acquired the target in stage one and that the incumbent attempts to sell the restructured firm to a competitor. From Lemma 1, we know that the trade sale price in stage three is $S^{3}=R_{A}(r)-R_{N A}(r)$. We also know the profits from competing with a rival who possesses the target are $R_{N A}(r)$. Thus, the total profits from selling the target and remaining in the industry would be $S^{3}-F+R_{N A}(r)$ or $R_{A}(r)-R_{N A}(r)-F+R_{N A}(r)=R_{A}(r)-F$. But then it is clear that an incumbent buying to sell implements the same governance structure as an incumbent buying to keep $\left(g_{k}^{*}=\arg \max _{g}\left[R_{A}(g)-C(g)-F\right]\right)$ and Propositions 1 and 2 still hold. Essentially, the incumbent buying to sell internalizes the effect on its other assets when determining the governance structure leading to the same restructuring intensity as an incumbent buying to keep.

But cannot the incumbent sell all of its assets and completely exit the industry? This is possible, but if it is profitable or not will depend on the classical merger profitability condition (see Salant et al. (1983)). In our setting, a full exit by an incumbent committed to sell occurs if the following condition holds:

$$
\underbrace{R_{A}\left(g_{s}^{*} ; n-1\right)-R_{s A}\left(g_{s}^{*} ; n-1\right)-C\left(g_{s}^{*}\right)-F}_{\text {Profits from selling and exiting (with concentration effect), }}>\underbrace{R_{A}\left(g_{k}^{*} ; n\right)-C\left(g_{k}^{*}\right)}_{\text {Profits from staying }},
$$

An exit leads to a concentration of the market since there are only $n-1$ incumbents remaining in the market. In general, the sign of equation (14) depends on merger and market-specific characteristics such as level of concentration in the market and asset complementarities. For example, if the asset 
complementarities are sufficiently low, and the market power increase caused by the merger is sufficiently low, the incumbent will not have the incentives to completely exit the industry.

Remark 2 (Allowing non-acquirers to respond). Overinvestment incentives in the baseline model will remain if we allow non-acquirers to invest in restructuring and replace Assumption 1 with assumption that restructuring activities are strategic substitutes: $\frac{\partial R_{A}}{\partial r_{k}}>0, \frac{\partial R_{A}}{\partial r_{s}}>0 \frac{\partial R_{A}}{\partial r_{n a}}<0, \frac{\partial R_{N A}}{\partial r_{n a}}>0, \frac{\partial R_{N A}}{\partial r_{k}}<0$, $\frac{\partial R_{N A}}{\partial r_{s}}<0, \frac{\partial^{2} R_{A}}{\partial r_{k} \partial r_{N A}}<0$ and $\frac{\partial^{2} R_{A}}{\partial r_{s} \partial r_{N A}}<0$. Here, $r_{k}$ denotes restructuring by an acquiring incumbent, $r_{N A}$ denotes restructuring by a non-acquiring incumbent and $r_{s}$ denotes restructuring by a private equity backed firm. To see that our results hold, suppose first that an incumbent acquired the target in stage one and that the managers decision on $r^{*}(g)$ is unaffected. An acquiring incumbent and non-acquiring incumbents invest in governance such that for the incumbent $g_{k}^{*}=\arg \max _{g_{k}}\left[R_{A}\left(g_{k}, g_{N A k}\right)-C\left(g_{k}\right)-F\right]$, and for each non-acquiring incumbent $g_{N A k}^{*}=\arg \max _{g_{N A}}\left[R_{A}\left(g_{k}, g_{N A k}\right)-C\left(g_{N A k}\right)-F\right]$. The Nashequilibrium in governance $\left(\left\{g_{k}^{*}, g_{N A k}^{*}\right\}\right)$ is obtained from

$$
\begin{aligned}
\frac{d R_{A}\left(g_{k}^{*}, g_{N A k}^{*}\right)}{d r_{k}} \frac{d r_{k}^{*}}{d g_{k}} & =C^{\prime}\left(g_{k}^{*}\right), \text { and } \\
\frac{d R_{N A}\left(g_{k}^{*}, g_{N A k}^{*}\right)}{d r_{N A}} \frac{d r_{n a}^{*}}{d g_{N A k}} & =C^{\prime}\left(g_{n a k}^{*}\right) .
\end{aligned}
$$

If a private equity firm obtained the target in stage one, the private equity firm and non-acquiring incumbents invest to improve governance such that for the private equity backed firm $g_{s}^{*}=\arg \max _{g_{s}}\left[S^{3}-\right.$ $\left.C\left(g_{s}\right)-(F-\Delta)\right]$ with $S^{3}=R_{A}\left(g_{s}, g_{N A s}\right)-R_{N A}\left(g_{s}, g_{N A s}\right)$, and for each non-acquiring incumbent $g_{N A s}^{*}=\arg \max _{g_{N A s}}\left[R_{A}\left(g_{s}, g_{N A s}\right)-C\left(g_{N A s}\right)-F\right]$. The Nash equilibrium $\left(\left\{g_{s}^{*}, g_{N A s}^{*}\right\}\right)$ is obtained from

$$
\begin{aligned}
{\left[\frac{d R_{A}\left(g_{s}^{*}, g_{N A s}^{*}\right)}{d r_{s}}-\frac{d R_{N A}\left(g_{s}^{*}, g_{N A s}^{*}\right)}{d r_{s}}\right] \frac{d r_{s}^{*}}{d g_{s}} } & =C^{\prime}\left(g_{s}^{*}\right), \text { and } \\
\frac{d R_{N A}\left(g_{s}^{*}, g_{N A s}^{*}\right)}{d r_{N A}} \frac{d r_{N A}^{*}}{d g_{N A s}} & =C^{\prime}\left(g_{N A s}^{*}\right) .
\end{aligned}
$$

Comparing the first order conditions that determine the Nash equilibrium, we can see that a private equity backed firm implements stronger governance and induces more restructuring than an incumbent $\left(r_{s}^{*}\left(g_{s}^{*}\right)>r_{k}^{*}\left(g_{k}^{*}\right)\right)$ and that non-acquirers invest less in governance and restructuring when the target is private equity backed compared to when the target is acquired by an incumbent $\left(r_{N A}^{*}\left(g_{N A s}^{*}\right)<\right.$ $\left.r_{N A}^{*}\left(g_{N A k}^{*}\right)\right)$. These results follow from the fact that investments are strategic substitutes. Since investments in inducing restructuring are strategic substitutes, the non-acquiring incumbents prefer to reduce their investments if the target is private equity backed since private equity firms have stronger incentives to induce restructuring in the target than incumbents. That restructuring activities are strategic substitutes ensures us that $r_{s}^{*}\left(g_{s}^{*}\right)>r_{k}^{*}\left(g_{k}^{*}\right)$. But what if they are strategic complements? Then, we could still have that $r_{s}^{*}\left(g_{s}^{*}\right)>r_{k}^{*}\left(g_{k}^{*}\right)$, even though $r_{N A}^{*}\left(g_{N A s}^{*}\right)>r_{N A}^{*}\left(g_{N A k}^{*}\right)$. However, it could now equally well be that incumbents become so aggressive in restructuring that $r_{s}^{*}\left(g_{s}^{*}\right)>r_{k}^{*}\left(g_{k}^{*}\right)$ no longer holds and then overinvestment will not occur.

\section{Welfare Effects of Temporary Ownership}

Overinvestment is beneficial for consumers as marginal costs (and thereby prices) are reduced, but it hurts rival firms in the industry. The balance of these two effects determine the impact on total welfare. To compare the first-best levels of governance and restructuring to the privately optimal ones, define total welfare as

$$
W(g)=R_{A}(g)-C(g)-F+(n-1) R_{N A}(g)+C S(g),
$$

where, for simplicity, the we omit the manager. ${ }^{20}$ The first three terms correspond to producer surplus while the last term captures consumer surplus. The acquisition price does not appear in the producer surplus part because it is netted out between the acquiring firm and the target. If we make the reasonable assumption that stronger governance and more restructuring leads to lower market prices, then the reduced-form consumer surplus $C S(g) \equiv C S\left(r^{*}(g)\right)$ is increasing in governance and restructuring: $(d C S / d r)\left(d r^{*} / d g\right)>0$. To ensure that a first-best interior optimum exists defined as $W^{*}=W\left(g^{*}\right)$ for

\footnotetext{
${ }^{20}$ Formally, the assumption we make is that $\partial w / \partial g$ is zero. We conjecture that the results in Proposition 3 below will hold if $\partial w / \partial g$ is not too negative.
} 
Figure 3: First-best in relation to temporary and permanent ownership.

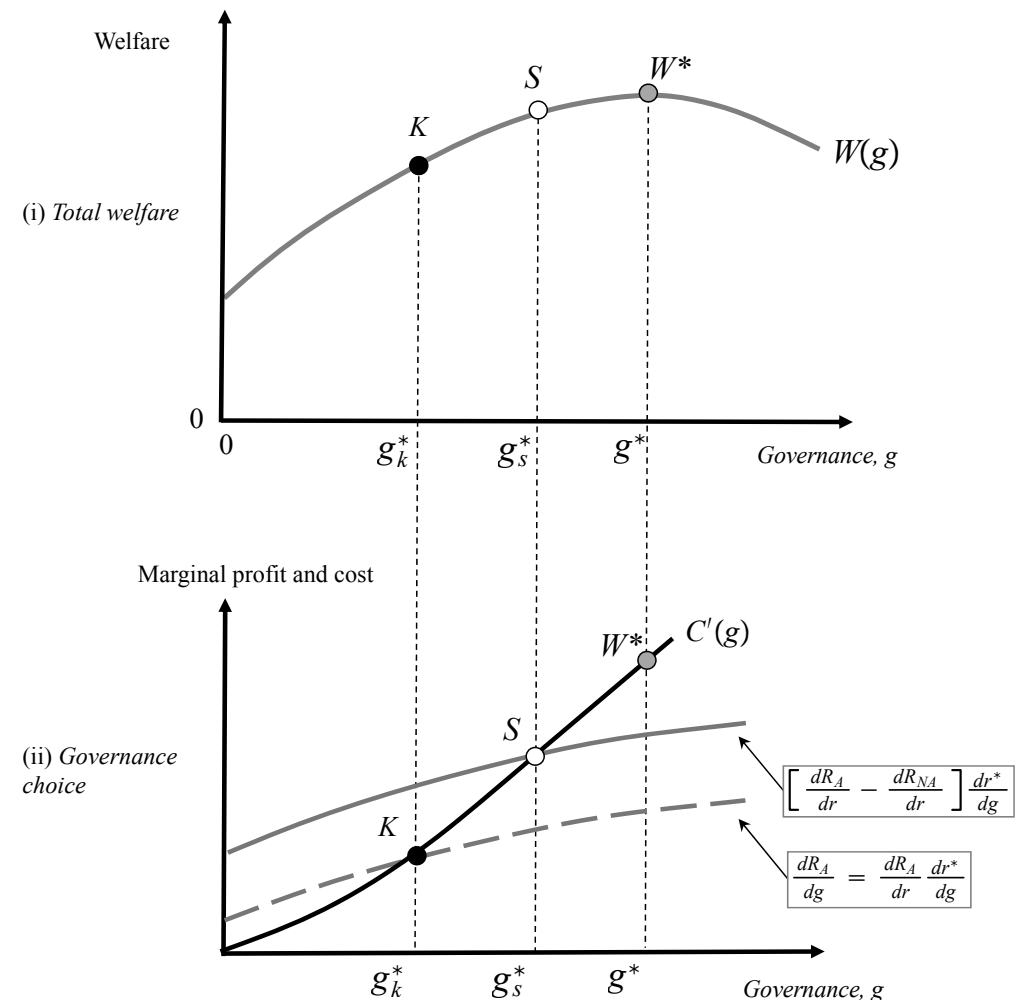

Notes. Part (i) illustrates that overinvestment by temporary ownership brings governance and restructuring levels closer to the first best optimum $g^{*}$ if $d W\left(g_{s}^{*}\right) / d g>0$ (the tangent at point $S$ is upwards sloping). Otherwise overinvestment by temporary owners can lead to excessive governance structures and restructuring incentives in relation to first-best. Part (ii) displays how different objective functions result in higher governance and restructuring under temporary ownership compared to permanent ownership.

$g^{*}=\arg \max _{g} W(g)$, we assume that $d W(0) / d g>0$ and that $C(g)$ is sufficiently convex so that $W(g)$ is strictly concave. We can then state the following proposition.

Proposition 3. Temporary ownership increases total surplus $\left(W\left(g_{s}^{*}\right)>W\left(g_{k}^{*}\right)\right)$ if $d W\left(g_{s}^{*}\right) / d g>0$. In the Linear Quadratic Cournot model (specified in Example 1), this occurs when (i) temporary owners acquire good targets and make them great (such that the ex-post market share, output or price-cost margin is relatively high), (ii) when there are few rivals in the market, and (iii) when the marginal costs of governance and restructuring are low.

The proposition says that when $d W\left(g_{s}^{*}\right) / d g>0$ holds, temporary ownership takes equilibrium governance and restructuring efforts closer to the first best $\left(g^{*}>g_{s}^{*}>g_{k}^{*}\right)$. From Proposition 1 we know that $g_{s}^{*}>g_{k}^{*}$ and if the total surplus function is non-decreasing at the optimal level of governance for a temporary owner $\left(d W\left(g_{s}^{*}\right) / d g>0\right)$, then temporary ownership must increase total surplus relative to permanent ownership if the welfare function is strictly concave. The intuition is illustrated in Figure 3. Figure 3(ii) displays how the incentive to maximize the trade sale price brings governance levels up to point $S$ from $K$ under permanent ownership. Figure 3(i) then illustrates the effect on total welfare of the overinvestment. Total welfare increases since $S$ is closer to the first best outcome $W^{*}$.

Figure 3(i) also makes it clear that temporary ownership could decrease total welfare if overinvestment pushes $S$ to the right of $W^{*}$ (which occurs if $d W\left(g_{s}^{*}\right) / d g<0$ ). A sufficient condition for total welfare to decrease is if point $K$ is to the right of $W^{*}$, so a permanent owner also invests too much $\left(g_{k}^{*}>g^{*}\right)$. Then, temporary ownership unambiguously decreases welfare. If $K$ is located to the left of $W^{*}$ and $S$ is located to the right of $W^{*}$, a trade-off exists between too low governance under permanent ownership $\left(g_{k}^{*}<g^{*}\right)$ and too high governance levels under temporary ownership $\left(g_{s}^{*}>g^{*}\right)$.

To get a sense for when temporary ownership increases welfare, we make use the Linear Quadratic Cournot model. Total surplus can be rewritten as $W(g)=S^{3^{*}}(g)-C(g)-F+n R_{N A}(g)+C S(g)$ using 
Figure 4: Total welfare in the Linear Cournot model.

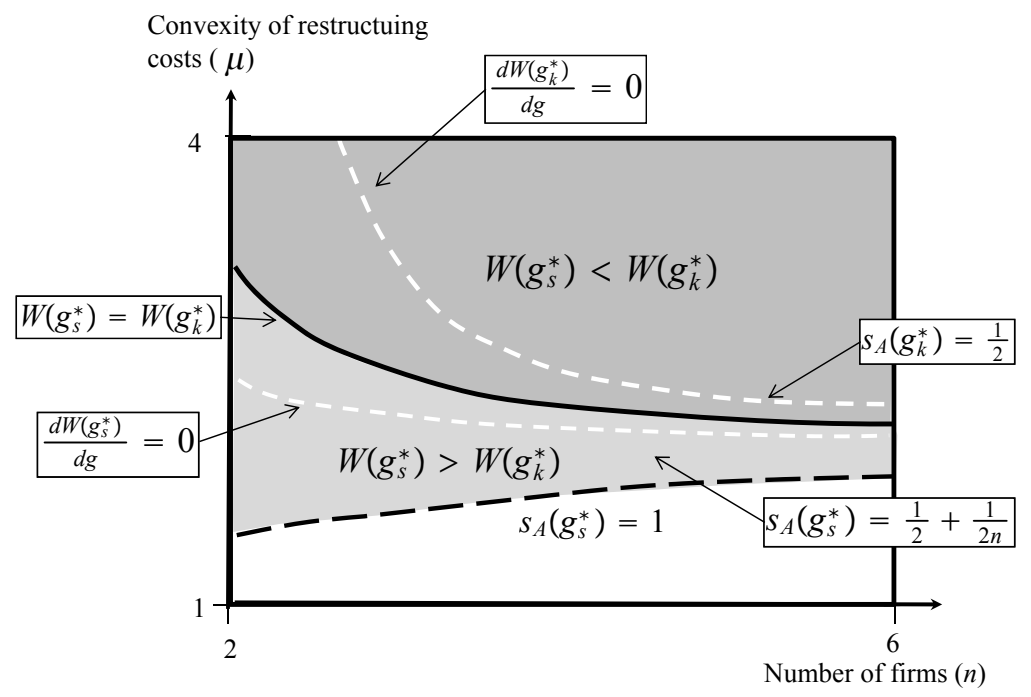

Notes. The figure illustrates how in the Linear Cournot model overinvestment by temporary owners leads welfare increases or decreases depending on governance and restructuring costs $\mu$ and the number of firms in the industry $n$.

$S^{3^{*}}(g)=R_{A}(g)-R_{N A}(g)$. From the envelope theorem we then obtain

$$
\frac{d W\left(g_{s}^{*}\right)}{d g}=C S_{g}^{\prime}\left(g_{s}^{*}\right)+n \frac{d R_{N A}\left(g_{s}^{*}\right)}{d g} .
$$

The first term gives the positive externality on consumers through increased restructuring whereas the second term shows the negative externality on rivals' profits. In the Linear Quadratic Cournot model (assuming that $r^{*}(g)=g$ and noting that $s_{A}\left(g_{s}^{*}\right)+(n-1) s_{N A}\left(g_{s}^{*}\right)=1$ ) equation (18) becomes

$$
\frac{d W\left(g_{s}^{*}\right)}{d g}=\frac{n Q\left(g_{s}^{*}\right)}{n-1}\left[s_{A}\left(g_{s}^{*}\right)-\left(\frac{1}{2}+\frac{1}{2 n}\right)\right] \frac{d Q\left(g_{s}^{*}\right)}{d g} .
$$

Equation (19) is positive whenever the ex-post market share of the firm owning the restructured assets $\left(s_{A}\left(g_{s}^{*}\right)=q_{A}^{*}\left(g_{s}^{*}\right) / Q\left(g_{s}^{*}\right)\right)$ is sufficiently large (above $\left.1 / 2+1 / 2 n\right)$. Intuitively, the negative effects on rivals in the industry from overinvestment are small because rivals' output or price-cost margin $\left(q_{N A}^{*}\left(g_{s}^{*}\right)=\right.$ $\left.P\left(g_{s}^{*}\right)-c\right)$ are small. ${ }^{21}$ The low output or price cost margin stems from a low product market price $\left(P\left(g_{s}^{*}\right)\right)$ induced by higher ex-post governance $\left(q_{A}^{*}\left(g_{s}^{*}\right)\right)$. At the same time, the effect on consumer surplus is greater because of a lower price on a larger total sales volume $\left(Q\left(g_{s}^{*}\right)\right)$.

Let us now illustrate that total welfare increases (the ex-post market share of the firm owning the restructured assets is large) when there are few rivals in the market ( $n$ is small), and when the marginal costs of governance and restructuring are low ( $\mu$ is low). Figure 4 depicts the welfare differential $W\left(g_{s}^{*}\right)-$ $W\left(g_{k}^{*}\right)$ over the convexity of the cost function $C(g)$, as measured by the efficiency parameter $\mu$, and the number of incumbent firms $n \geq 2$. Below the dashed white line (corresponding to $d W\left(g_{s}^{*}\right) / d g=$ $0)$, the firm owning the restructured assets has a large market share: $s_{A}\left(g_{s}^{*}\right)>(1 / 2+1 / 2 n)$. This occurs when governance and restructuring costs $\mu$ are low and the number of rivals $n$ is low. Since $d W\left(g_{s}^{*}\right) / d g>0$, temporary ownership increases total welfare $\left(S\right.$ and $K$ are to the left of $W^{*}$ in Figure $3)$. The locus $s_{A}^{*}\left(g_{S}^{*}\right)=1$ provides a lower bound on $\mu$ as rivals need have a positive market share. At higher restructuring costs, the market share of rivals will increase. In the north-east region of the diagram, the welfare differential, evaluated at the optimal governance by a permanent owner, is negative, $d W\left(g_{k}^{*}\right) / d g=2 Q\left(g_{k}^{*}\right)\left[s_{A}\left(g_{k}^{*}\right)-1 / 2\right]\left(d Q\left(g_{s}^{*}\right) / d g\right)<0$, as $s_{A}\left(g_{k}^{*}\right)>1 / 2$. With overinvestment, $g_{s}^{*}>g_{k}^{*}$, temporary ownership reduces welfare: $W\left(g_{s}^{*}\right)<W\left(g_{k}^{*}\right)$ (points $S$ and $K$ will be to the right of the first best $W^{*}$ in Figure 3). In the middle region, a trade-off between too low incentives under permanent ownership and too high incentives under temporary ownership exists.

\footnotetext{
${ }^{21}$ The second term in equation (18) becomes $n d R_{N A}\left(g_{s}^{*}\right) / d g=n P_{g}^{\prime}\left(g_{s}^{*}\right) q_{N A}^{*}\left(g_{s}^{*}\right)<0$. This follows from $\frac{d R_{N A}\left(g_{s}^{*}\right)}{d g}=$ $\frac{\partial R_{N A}}{\partial g}+\frac{\partial R_{N A}}{\partial q_{N A}} \frac{d q_{N A}^{*}}{d g}+\frac{\partial R_{N A}}{\partial q_{-N A}} \frac{d q-*}{d g}$, where $\frac{\partial R_{N A}}{\partial g}=\frac{\partial R_{N A}}{\partial q_{N A}}=0$. Since $R_{N A}\left(g_{s}^{*}\right)=\left(P\left(g_{s}^{*}\right)-c\right) q_{N A}^{*}$, it follows that $\frac{d R_{N A}\left(g_{s}^{*}\right)}{d g}=P_{g}^{\prime} q_{N A}^{*}$ where $P_{g}^{\prime}=\frac{d P}{d q_{-N A}} \frac{d q_{-N A}^{*}}{d g}<0$. In this expression, $q_{-N A}$ is the output of the rivals to a non-acquiring permanent owner. It holds that $d q_{-N A}^{*} / d g>0$.
} 


\section{Antitrust Policy}

In most countries the market for corporate control in concentrated markets is scrutinized by an anti-trust authority. When evaluating a merger, antitrust authorities in most jurisdictions estimate whether efficiency gains are likely to offset the higher market power enjoyed by the merging firms, or not. According to the US Merger Guidelines by the US Department of Justice, they ". . .will not challenge a merger if cognizable efficiencies are of a character and magnitude such that the merger is not likely to be anticompetitive in any relevant market. To make the requisite determination, the Agency considers whether cognizable efficiencies likely would be sufficient to reverse the merger's potential to harm consumers in the relevant market, e.g. by preventing price increases in that market." 22 This corresponds to the antitrust authority maximizing consumer surplus. Following Motta and Vasconcelos (2005) and Fumagalli et al. (2009), suppose that the antitrust authority is forward looking such that it considers whether other mergers could occur if a merger is blocked or allowed and that it accounts for the implications of such alternative mergers on consumer surplus. ${ }^{23}$

\subsection{A Generalized Model}

To analyze antitrust policy, we need to extend the baseline model to account for exits through an initial public offering (IPO) in stage three (for the structure of the game, see Figure 1). This analysis becomes quite involved so we refer to appendix B for details. Formally, we model an IPO as a sale of the restructured target to a firm outside the industry. It can also refer to selling the restructured target to dispersed shareholders or selling the firm to another private equity firm (secondary buyout) who ends up producing in the market. Thus, if a private equity firm has bought the target in stage one, in the exit stage three incumbents and outsiders simultaneously post bids on the restructured target, which are accepted or rejected by the private equity firm. In the generalized model, we also incorporate the target's decision to sell allowing it reject the bids in stage one and remain as an independent firm on the market.

We now give a brief description of the generalized model. To extend the exit choice in stage three to incorporate IPOs, let $R_{A}(r, k)$ be the profit the incumbent acquirer, and $R_{N}(r, k)$ be the profit of a non-acquirer an incumbent acquisition. Furthermore, let $R_{S}(r, s)$ be the profit of an outsider when obtaining the target through an IPO and let $R_{N}(r, k)$ be the profit of a non-acquirer when an IPO occur. Then, the value to preempt an incumbent rival in stage three is $\omega_{k k}=R_{A}(r, k)-R_{N A}(r, k)$, the value for an incumbent to deter IPO is $\omega_{k I P O}=R_{A}(r, k)-R_{N A}(r, s)$ and the value of an IPO is $\omega_{I P O}=R_{S}(r, s)-G$ where $G$ is an exogenous IPO cost. In the appendix, we show that high levels of restructuring are conducive to exit though trade sale. This occurs since incumbents valuations increase since obtaining a more restructured target increases the profit as acquirer but also reduces the profit the incumbent would receive if not acquiring the target as competition increases. The value of IPO on the other hand only increases in the profit of the profit received by the outsider.

Given the knowledge of how the outcome of the exit game depends level of restructuring, a private equity firm sets governance in stage two to influence the amount of restructuring $r^{*}(g)$ to maximize the reward to exit though the IPO value or the acquisition price in a trade sale. An incumbent obtains the target again restructures it to maximize its net profit. As before, this produces stage one valuations, $v_{k k}$, $v_{k s}$ and $v_{s}$. If the target is sold to a private equity firm in stage one and restructured for an exit though an IPO in stage three, the reduced-form product market profit for an outsider is $R_{S}\left(g_{s}^{I P O}, s\right)$ generating a value in stage one for the private equity firm of $v_{I P O}=R_{S}\left(g_{s}^{I P O}, s\right)-C\left(g_{s}^{I P O}\right)-(F-\Delta)-G$, where $g_{s}^{I P O}=\arg \max _{g}\left[R_{S}\left(r^{*}(g), s\right)-C(g)\right]$ is the optimal governance to induce restructuring in stage two. Non-acquiring incumbents then have reduced-form profits $R_{S}\left(g_{s}^{I P O}, s\right)$. Assume that the target cannot profitably restructure itself in stage two (setting $g_{t}^{*}=0$ ). If the target rejects the bids in stage one it will have the reduced-form profit $R_{T}(0, t)$, which is also the reservation price $v_{t}$. The profit for incumbent rivals are then $R_{N A}(0, t)=R_{T}(0, t)$.

Thus, in the generalized model the potential ownership of the target in stage one involves incumbent ownership $(l=k)$, private equity ownership $(l=s)$ and target ownership $(l=t)$. The value for an incumbent of buying the target will is $v_{k l}$ for $l=t, k, s$. Finally, let $C S(g, l) \equiv C S\left(r^{*}(g), l\right)$ to denote

\footnotetext{
${ }^{22}$ US Merger Guidelines, revised April 8, 1997, Section 4.

${ }^{23}$ Nocke and Whinston (2010) describes under what circumstances a myopic antitrust authority does equally well as a forward-looking one. The conditions under which this occurs are not fulfilled in our setting because firms could be involved in multiple mergers (the set of mergers is not disjoint) and because of heterogeneity in ownership types (private equity firms maximize the trade sale price, which gives different incentives for mergers compared to maximizing product market profits).
} 
the reduced-form consumer surplus. Again note that better governance increases consumer welfare $\left.(d C S / d r)\left(d r^{*} / d g\right)>0\right)$ and that consumer surplus is also increasing in the number of firms active in the market.

\subsection{Effects of an Active Private Equity Market}

In the generalized model, we can now state the following proposition:

Proposition 4. With a forward looking consumer welfare maximizing antitrust authority, the emergence of an active private equity market will increase consumer welfare through

(i) triggering otherwise unprofitable but consumer welfare enhancing mergers among incumbents; or through

(ii) preserving competition in the market by acquiring the target and undertaking an IPO.

To see the first part of the proposition, suppose that there is initially no private equity sector active. This could be because the private equity firms do not have sufficient restructuring advantages $(\Delta$ low $)$ or that IPO costs are high $\left(G\right.$ high). Private equity firms cannot then outbid the target: $v_{t}>\max \left\{v_{s}, v_{I P O}\right\}$. An acquisition by an incumbent of the target is the only possible merger and will be allowed by the antitrust authority if $C S\left(g_{k}^{*}, s\right)>C S(0, t)$.

The merger will not, however, take place if the initial market structure is merger stable: if $v_{t}>$ $v_{k I P O}>v_{k k}$. While the antitrust authority can block consumer welfare reducing mergers, it cannot force firms to merge when the merger is beneficial for consumers but is not privately profitable (as pointed out by Salant et al. (1983)). Private equity firms can alleviate this problem by threatening to buy the target. To see this, suppose that an active private equity market develops and that the IPO cost is slightly above a threshold $\bar{G}$ such that $v_{s}=v_{I P O}$. Then, $v_{s}>v_{I P O}$ holds. Private equity firms will then bid higher than the reservation price of the target. Incumbents will anticipate that private equity firms will use strong governance structures to induce restructuring in stage two to create bidding competition in a trade sale in stage three. From Proposition 2, an incumbent then has an incentive to preempt such overinvestment since $v_{k s}>v_{s}$. Hence, the mere threat of a private equity buyout is enough to trigger the otherwise privately unprofitable merger.

To prove the second part of Proposition 4, note that while the antitrust authority will recognize that an incumbent acquisition can increase consumer welfare compared to no acquisition taking place $\left(C S\left(g_{k}^{*}, s\right)>C S(0, t)\right)$, it will also infer that consumer welfare could be further improved by encouraging a buyout and imposing restrictions on the exit auction. Encouraging trade sales has the benefit of ensuring stronger incentives to improve governance and conduct restructuring. Indeed, under a trade sale $C S\left(g_{s}^{*}, k\right)>C S\left(g_{k}^{*}, k\right)$ follows directly since private equity firms maximize the sales price. Encouraging IPOs, on the other hand, has the benefit of ensuring that the number of firms in the industry stays constant. An active private equity market can then help prevent concentration in the market while still ensuring that governance is improved and restructuring is undertaken. Which exit mode the antitrust authority prefers will depend on whether the benefit to consumers from overinvestment under trade sales outweighs the benefit to consumers of preventing concentration in the market under an IPO. ${ }^{24}$

More generally, the analysis in appendix $\mathrm{B}$ also shows that overinvestment in governance and restructuring will still occur when exit through an IPO is possible. However, when the focus is on exiting through an IPO, strategic product market effects matter less for the exit valuation and so governance and restructuring incentives are weaker as compared to when the focus is on exiting through a trade sale.

\section{Incentives to Specialize}

Let us close the baseline model by showing that temporary ownership provides incentives for specializing in restructuring because the scarce resource of having lower fixed restructuring costs $\Delta$ can be spread over several markets sequentially. To capture this in a simple way, we endogenize $\Delta$ by adding a stage zero to our baseline model with trade sales (no IPOs or antitrust authority). In this stage, incumbents and private equity firms can invest in acquiring restructuring skills by increasing the fixed restructuring cost advantage $\Delta$. The incumbents and the private equity firms choose simultaneously whether to retain

\footnotetext{
${ }^{24}$ Note that we could potentially allow other outside entrants to participate in the initial acquisition auction as well. However, to be able to play a role in equilibrium, the outside entrant would have to be sufficiently good (better than the private equity firms) at restructuring the target firm's assets. But being restructuring specialists is exactly our definition of private equity firms, so such an outside entrant would then be formally equivalent to a private equity firm buying targets to later place them on the market through an IPO and as such the model would remain unchanged.
} 
Table 1: Payoff matrix for specializing in restructuring.

\begin{tabular}{c|cc|cc|} 
& \multicolumn{1}{c}{ Abstain } & \multicolumn{2}{c}{ Invest $\Psi$} \\
\multicolumn{1}{c}{$\left(\Delta_{k}=0\right)$} & \multicolumn{2}{c}{$\left(\Delta_{k}=\Delta\right)$} \\
\cline { 2 - 5 } Abstain & $\pi_{s}(0,0)$ & & $\pi_{s}(0, \Delta)$ & \\
$\left(\Delta_{s}=0\right)$ & & $\pi_{k}(0,0)$ & & $\pi_{k}(\Delta, 0)$ \\
\cline { 2 - 4 } Invest $\Psi$ & $\pi_{s}(\Delta, 0)$ & & $\pi_{s}(\Delta, \Delta)$ & \\
$\left(\Delta_{s}=\Delta\right)$ & & $\pi_{k}(0, \Delta)$ & & $\pi_{k}(\Delta, \Delta)$ \\
\cline { 2 - 4 } & & &
\end{tabular}

Notes. This table displays the pay-off matrix depicting a private equity firm's investment strategy horizontally and an incumbent's investment strategy vertically.

the fixed restructuring cost $F$, or to invest in acquiring specialized restructuring skills at cost $\Psi$ providing fixed restructuring costs of $F-\Delta$. Private equity firms participate in the bidding of targets in $d$ separate markets which are segmented on the demand side. Incumbents face costs in learning how to produce in new markets and only participate in the bidding over a target in their own market (such costs are avoided by private equity firms since they buy to sell and do not remain in the market).

To see this, consider a situation where one private equity firm and one incumbent chooses between investing and not investing. Other private equity firms will not invest if they believe that a rival private equity firm, or an incumbent, will invest as they cannot cover the investment cost from the resulting bidding competition over the target. Assuming that the fixed cost advantage from investing is not too large, incumbents will not challenge a rival incumbent acquisition in stage one due to the free-riding effect of an acquisition. Then, incumbents have no incentive to invest given that a rival incumbent invests.

Table 1 depicts the net profits of the incumbent $(k)$ and the private equity firm $(s)$, given that other private equity firms and incumbents choose not to invest. Let us examine when \{Invest, Abstain $\}$ is a unique equilibrium, i.e. under what conditions does the private equity firm $s$ choose "Invest" and the incumbent $k$ choose "Abstain".

Suppose the private equity firm choose to invest if the incumbent chooses not to invest. When only one private equity firm invests, the acquisition price is $S^{1}=v_{k s}=\bar{v}_{k s}-F$, where we use a bar to denote stage one valuations gross of fixed restructuring costs. The net profit for the private equity firm is then $\pi_{s}(\Delta, 0)=\bar{v}_{s}-(F-\Delta)-S^{1}-\Psi / d$, where the investment cost $\Psi$ is spread out on each market with a potential target. Without investing the private equity firm cannot outbid the incumbent, $\pi_{s}(0,0)=0$. The private equity firm will then choose to invest if $\pi_{s}(\Delta, 0)-\pi_{s}(0,0)>0$, or if

$$
\Delta>\bar{v}_{k s}-\bar{v}_{s}+\frac{\Psi}{d}=\bar{\Delta}+\frac{\Psi}{d} .
$$

Intuitively, the fixed cost reduction in restructuring must be greater than the per market investment cost $\Psi / d$ and the incentive for the incumbent to preempt overinvestment in restructuring in a future trade sale $\left(\bar{\Delta}=\bar{v}_{k s}-\bar{v}_{s}\right.$ from Proposition 2). Above the locus $\Delta=\bar{v}_{k s}-\bar{v}_{s}+\Psi / d$ labeled the private equity investment condition in Figure 5, the private equity firm has an incentive to invest, given that the incumbent does not invest. If the incumbent would invest, the private equity firm cannot outbid the incumbent in the acquisition game in stage one and would therefore make a loss on investing: $\pi_{s}(\Delta, \Delta)=-\Psi / d$.

Let us now examine when "Abstain" is a dominating strategy for the incumbent, starting with the incumbents incentive to preempt an investment by the private equity firm. The incumbent needs to pay the valuation of the private equity firm in stage one $\left(S^{1}=v_{s}=\bar{v}_{s}-(F-\Delta)\right)$ which gives a net profit of $\pi_{k}(\Delta, \Delta)=R_{A}\left(g_{k}^{*}\right)-C\left(g_{k}^{*}\right)-(F-\Delta)-S^{1}-\Psi$. If the incumbent abstains, a buyout will occur, and its net profit becomes $\pi_{k}(0, \Delta)=R_{N A}\left(g_{s}^{*}\right)$. Consequently, the incumbent will not preempt the investment by the private equity firm if $\pi_{k}(0, \Delta)>\pi_{k}(\Delta, \Delta)$, or if:

$$
\Psi>\bar{v}_{k s}-\bar{v}_{s}=\bar{\Delta}
$$

To the right of the locus $\Psi=\bar{\Delta}$, labeled the incumbent preemption condition in Figure 5 , the incumbent will not invest when the private equity firm has invested. Intuitively, the incumbent abstains if the incentive to preempt excessive restructuring is smaller than the investment cost.

Examine next the incumbent's incentive to invest if that the private equity firm chooses not to invest. Then, an incumbent acquisition occurs in stage one at the valuation of the private equity firm: $S^{1}=v_{s}=\bar{v}_{s}-F$. It follows that net profit for the incumbent when investing is $\pi_{k}(\Delta, 0)=R_{A}\left(g_{k}^{*}\right)-$ 
Figure 5: Specialization in equilibrium.

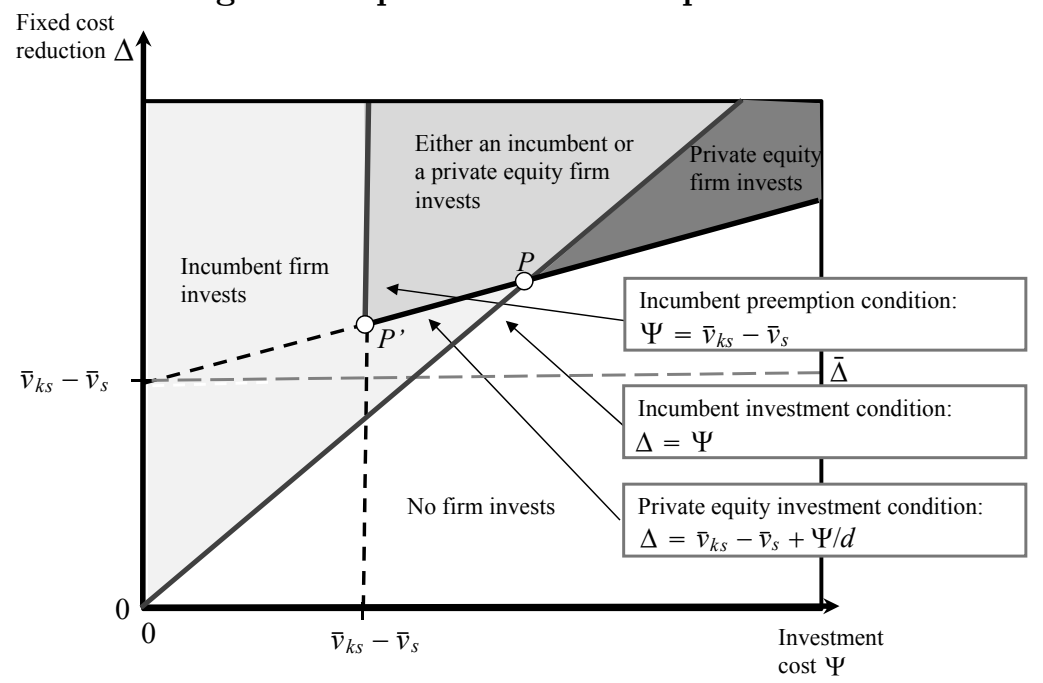

Notes. This figure illustrates the solution to the stage zero investment game for different values of the cost of specializing in restructuring $(\Psi)$ and the fixed restructuring cost $(F)$. The more markets $d$ private equity firms can invest in, the more likely it is that a unique equilibrium exists in which only private equity firms invest in acquiring specialized restructuring skills.

$C\left(g_{k}^{*}\right)-(F-\Delta)-S^{1}-\Psi$, whereas the net profit when not investing is $\pi_{k_{1}}(0,0)=R_{A}\left(g_{k}^{*}\right)-C\left(g_{k}^{*}\right)-F-S^{1}$. Consequently, the incumbent will not invest if $\pi_{k}(0,0)>\pi_{k}(\Delta, 0)$, which corresponds to

$$
\Psi>\Delta .
$$

The locus $\Psi=\Delta$ is labeled the incumbent investment condition and also shown in Figure 5. The figure reveals that four types of equilibria can occur. We obtain the following proposition.

Proposition 5. There exists a unique equilibrium in which only private equity firms invests in acquiring restructuring skills in stage zero if the number of markets d with potential targets is sufficiently high: if $\Psi>\Delta>\bar{v}_{k s}-\bar{v}_{s}+\Psi / d$.

When investing into restructuring skills is relatively cheap $(\Delta / \Psi$ high) only the incumbent invests. When the cost of investing is relatively high $(\Delta / \Psi$ low $)$ no firm invests. When both the reward to investing $\Delta$ and the cost to investing $\Psi$ are fairly high multiple equilibria emerge. The equilibrium where only the private equity firm invests \{Invest, Abstain\}, emerges in the North-East region, below the incumbent investment condition and above the private equity investment condition. Intuitively, investment costs need to be sufficiently high to decrease the incentive for the incumbent to invest, while the reward in cost reduction cannot be too high as this would create too strong an incentive for the incumbent to invest. An essential element is that the number of markets $d$ needs to be sufficiently large to have only the private equity firm investing in equilibrium. With only one market the private equity investment locus in equation (20) would be parallel to the incumbent investment condition locus in equation (22). Then, only the region of multiple equilibria where either the private equity firm or the incumbent invests exist.

\section{Concluding remarks}

We have developed a theory of temporary ownership in oligopolistic markets underscoring three properties of temporary ownership. First, temporary ownership leads to overinvestment in governance and restructuring efforts relative to permanent ownership. Overinvestment increases consumer surplus but reduces producer surplus. Second, temporary owners can aid antitrust authorities in maximizing consumer surplus by triggering mergers in a merger stable industry or by preventing concentration in the industry. Third, temporary ownership gives incentives for specialization in temporary ownership. Our analysis suggests that private equity firms play an important role as challengers of existing oligopolies through aggressive restructuring of firms up for sale. We also underscore the important role played by antitrust authorities in ensuring that an active private equity market benefits consumers. 
Consistent with empirical evidence, our model predicts stronger governance structures, higher leverage, and increased productivity in the wake of buyouts. ${ }^{25}$ Our model is also consistent with evidence that rivals to acquired firms fare worse after the buyout. ${ }^{26}$ In terms of untested empirical predictions, our model suggests that exit by trade sale will occur when IPO costs are high, the marginal cost of governance is low and when governance (and subsequent restructuring) can significantly affect the target's as well as rival firm's net profits. Moreover, buyouts with little performance improvement in the target should predominately occur when exit takes place by an IPO. In the future, more empirical research into how exit and investment decisions are influenced by product market effects would be welcome.

\section{References}

Acharya, V. and C. Kehoe (2008). Corporate governance and value creation: Evidence from private equity. Working Paper, London Business School.

Amess, K. (2003). The effect of management buyouts on firm-level technical efficiency: evidence from a panel of UK machinery and equipment manufacturers. Journal of Industrial Economics 51, 35-44.

Axelson, U., T. Jenkinson, P. Strömberg, and M. S. Weisbach (2010). Borrow cheap, buy high? The determinants of leverage and pricing in buyouts. NBER Working Papers 15952, National Bureau of Economic Research, Inc.

Banal-Estanol, A. and M. Ottaviani (2006). Mergers with product market risk. Journal of Economics \& Management Strategy 15, 577-608.

Berle, A. and G. Means (1932). The Modern Corporation and Private Property. New York: The Commerce Clearing House.

Bolton, P. and D. Scharfstein (1990). A theory of predation based on agency problems in financial contracting. American Economic Review 80, 93-106.

Boucly, Q., D. Sraer, and D. Thesmar (2011). Growth LBOs. Journal of Financial Economics 102, $432-453$.

Brander, J. A. and T. R. Lewis (1986). Oligopoly and financial structure: The limited liability effect. American Economic Review 76, 956-970.

Brander, J. A. and T. R. Lewis (1988). Bankruptcy costs and the theory of oligopoly. Canadian Journal of Economics 21, 221-243.

Chen, H.-C. and J. R. Ritter (2000). The seven percent solution. Journal of Finance 55, 1105-1131.

Chevalier, J. A. (1995a). Capital structure and product-market competition: empirical evidence from the supermarket industry. American Economic Review 85, 415-435.

Chevalier, J. A. (1995b). Do LBO supermarkets charge more? An empirical analysis of the effects of LBOs on supermarket pricing. Journal of Finance 50, 1095-1112.

Coase, R. (1960). The problem of social cost. Journal of Law and Economics 3, 1-44.

Davis, S., J. Haltiwanger, R. Jarmin, J. Lerner, and J. Miranda (2009). Private equity, jobs and productivity., pp. 25-43. The Globalization of Alternative Investments Working Papers Volume 2: The Global Economic Impact of Private Equity Report 2009. Geneva: World Economic Forum.

Deneckere, R. and C. Davidson (1985). Incentives to form coalitions with Bertrand competition. RAND Journal of Economics 17, 473-486.

\footnotetext{
${ }^{25}$ For managerial ownership, see Kaplan (1989), Leslie and Oyer (2009) and Acharya and Kehoe (2008); for leverage see Axelson et al. (2010) and Leslie and Oyer (2009); and for productivity see Lichtenberg and Siegel (1990); Amess (2003); Harris et al. (2005) and Davis et al. (2009).

${ }^{26}$ This prediction is supported by the findings in Hsu et al. (2010), who find that stock prices of rival incumbents react negatively when a private equity firm acquires a firm in the industry. We would expect this to occur if the buyout comes as a surprise to the stock market or - in case the stock market has perfect foresight-if the buyout is a mixed equilibrium outcome in the acquisition game.
} 
Fabrizi, S., S. Lippert, P.-J. Norbäck, and L. Persson (2008). Venture capitalists, assymetric information, and ownership in the innovation process. IFN Working Paper No. 776.

Farrell, J. and C. Shapiro (1990). Horizontal mergers: An equilibrium analysis. American Economic Review 80, 107-126.

Frankel, M. E. S. (2005). Mergers And Acquisitions Basics: The Key Steps Of Acquisitions, Divestitures, And Investments. John Wiley \& Sons.

Friberg, R., P.-J. Norbäck, and L. Persson (2008). Getting a better price: Strategic behavior before changes in ownership of corporate assets. IFN Working Paper No. 777.

Fridolfsson, S.-O. and J. Stennek (2005). Why mergers reduce profits and raise share prices: a theory of preemptive mergers. Journal of the European Economic Association 3(5), 1083-1104.

Fumagalli, C., M. Motta, and L. Persson (2009). On the anticompetitive effect of exclusive dealing when entry by merger is possible. The Journal of Industrial Economics 57, 785-811.

Gilbert, R. J. and D. M. Newbery (1992). Alternative entry paths: the build or buy decision. Journal of Economics \& Management Strategy 1, 129-50.

Gilo, D., Y. Moshe, and Y. Spiegel (2006). Partial cross ownership and tacit collusion. Rand Journal of Economics 37, 81-99.

Gorbenko, A. and A. Malenko (2012). Strategic and financial bidders in takeover auctions. Available at SSRN: http://ssrn.com/abstract=1559481.

Gowrisankaran, G. (1999). A dynamic model of endogenous horizontal mergers. RAND Journal of Economics 30, 56-83.

Grossman, S. J. and O. D. Hart (1986). The costs and benefits of ownership: a theory of vertical and lateral integration. Journal of Political Economy 94, 691.

Harris, R., D. S. Siegel, and M. Wright (2005). Assessing the impact of management buyouts on economic efficiency: plant level evidence from the united kingdom. Review of Economics and Statistics 87, 148153.

Hart, O. D. and J. Moore (1990). Property rights and the nature of the firm. Journal of Political Economy 98, 1119-1158.

Hege, U., S. Lovo, M. Slovin, and M. Sushka (2012). Asset sales and the role of buyers: Strategic buyers versus private equity. Available at SSRN: http://ssrn.com/abstract=1787465.

Horn, H. and L. Persson (2001). The equilibrium ownership of an international oligopoly. Journal of International Economics 53, 307-333.

Hsu, S., A. Reed, and J. Rocholl (2010). Competitive effects of private equity investments. AFA 2011 Denver Meetings Paper. Available at SSRN: http://ssrn.com/abstract $=1571207$.

Jehiel, P. and B. Moldovanu (1999). Resale markets and the assignment of property rights. Review of Economic Studies 66, 971-991.

Jehiel, P. and B. Moldovanu (2000). Auctions with downstream interaction among buyers. RAND Journal of Economics 31, 768-791.

Jehiel, P., B. Moldovanu, and E. Stacchetti (1999). Multidimensional mechanism design for auctions with externalities. Journal of Economic Theory 85, 258-293.

Jensen, M. C. (1986). Agency costs of free cash flow, corporate finance and takeovers. American Economic Review 76, 323-329.

Jensen, M. C. (1989). The eclipse of the public corporation. Harvard Business Review 67, 61-74.

Jensen, M. C. and W. H. Meckling (1976). Theory of the firm: Managerial behavior, agency costs and ownership structure. Journal of Financial Economics 3, 305-360. 
Jovanovic, B. and P. Rousseau (2002). The q-theory of mergers. American Economic Review 92, 198-204.

Kamien, M. I. and I. Zang (1990). The limits of monopolization through acquisition. Quarterly Journal of Economics 105, 465-99.

Kaplan, S. N. (1989). The effects of management buyouts on operating performance and value. Journal of Financial Economics 24, 217-254.

Kaplan, S. N. and P. Strömberg (2009). Leveraged buyouts and private equity. Journal of Economic Perspectives 23, 121-146.

Katz, M. L. and C. Shapiro (1986). How to licence intangible property. Quarterly Journal of Economics 101, 567-590.

Kovenock, D. and G. Phillips (1995). Capital structure and product market rivalry: how do we reconcile the theory and the evidence. American Economic Review 85, 403-408.

Leslie, P. and P. Oyer (2009). Managerial incentives and value creation: Evidence from private equity. Available at SSRN: www.ssrn.com/abstract $=1341889$.

Lichtenberg, F. and D. S. Siegel (1990). The effects of leveraged buyouts on productivity and related aspects of firm behavior. Journal of Financial Economics 27, 165-194.

Maksimovic, V. (1988). Capital structure in repeated oligopolies. RAND Journal of Economics 19, 389-407.

Maksimovic, V. and G. Phillips (2002). Do conglomerate firms allocate resources inefficiently? evidence from plant-level data. Journal of Finance 57, 721-767.

Mankiw, G. N. and M. D. Whinston (1986). Free entry and social inefficiency. The RAND Journal of Economics 17, 48-58.

Martos-Vila, M., M. Rhodes-Kropf, and J. Harford (2012). Financial vs. strategic buyers. HBS Working Paper 12-098.

Motta, M. and H. Vasconcelos (2005). Efficiency gains and myopic antitrust authority in a dynamic merger game. International Journal of Industrial Organization 23, 777-801.

Nilssen, T. and L. Sorgard (1998). Sequential horizontal mergers. European Economic Review 42, $1683-1702$.

Nocke, V. and M. D. Whinston (2010). Dynamic merger review. Journal of Political Economy 118, 1201-1251.

Norbäck, P.-J. and L. Persson (2008). Entrepreneurial innovations, competition and competition policy. CEPR Discussion Paper No. DP6823.

Norbäck, P.-J. and L. Persson (2009). The organization of the innovation industry: Entrepreneurs, venture capitalists, and oligopolists. Journal of the European Economic Association 7, 1261-1290.

Norbäck, P.-J., L. Persson, and R. Svensson (2011). Creative destruction and productive preemption. CEPR Discussion Paper No. DP8281.

Norbäck, P.-J., L. Persson, and J. Tåg (2011). Acquisitions, entry and innovation in network industries. IFN Working Paper No. 867.

Olsson, M. and J. Tåg (2012). Private equity and employees. IFN Working Paper No 906.

Perry, M. K. and R. H. Porter (1985). Oligopoly and the incentive for horizontal merger. American Economic Review 75, 219-227.

Salant, S. W., S. Switzer, and R. J. Reynolds (1983). Losses from horizontal merger: The effects of an exogeneous change in industry structure on Cournot-Nash equilibrium. Quarterly Journal of Economics 98, 185-199, 185-199.

Strömberg, P. (2008). The new demography of private equity., pp. 1-26. The Globalization of Alternative Investments Working Papers Volume 1: The Global Economic Impact of Private Equity Report 2008. Geneva: World Economic Forum. 


\section{APPENDIX}

\section{A Proofs}

\section{A.1 Proof of Lemma 1}

Consider the equilibrium candidate $\mathbf{b}^{*}=\left(b_{1}^{*}, b_{2}^{*}, \ldots, b_{n}^{*}\right)$. Incumbent $w$ is the incumbent that has posted the highest bid and obtains the restructured target and firm $\varsigma$ is the incumbent with the second highest bid. Then, $b_{w}^{*} \geq \omega_{k k}$ is a weakly dominated strategy. $b_{w}^{*}<\omega_{k k}-\varepsilon$ is not an equilibrium, since firm $i \neq w$ then benefits from deviating to $b_{w}=b_{w}^{*}+\varepsilon$, since it will then obtain the restructured target and pay a price lower than its valuation of obtaining it. If $b_{w}^{*}=\omega_{k k}-\varepsilon$, and $b_{\varsigma}^{*} \in\left[\omega_{k k}-\varepsilon, S-2 \varepsilon\right]$, then no incumbent has an incentive to deviate, $b^{*}$ is a Nash equilibrium and the winning bid is $b_{w}^{*}=\omega_{k k}-\varepsilon=S^{3}(r)$.

\section{A.2 Proof of Lemma 2}

The bidders $y \in\{i \in\{1,2, . ., n\}, s \in\{1,2, . ., u\}\}$ are the $n$ incumbents $(i)$ and the $u$ outsiders $(s)$. Note first that any $b_{i} \geq \max \left\{\omega_{k k}, \omega_{k s}\right\}$ and $b_{s} \geq \omega_{s}$ is a weakly dominated strategy, since no bidder will post a bid equal to or above its maximum valuation of obtaining the target firm.

Inequality $\mathbf{I}$ Consider the equilibrium candidate $\mathbf{b}^{*}=\left(b_{1}^{*}, b_{2}^{*}, \ldots, b_{n+u}^{*}\right)$. Let us assume incumbent $w \neq s$ is the incumbent that has posted the highest bid and obtains the assets, and that firm $\varsigma \neq s$ is the incumbent with the second highest bid. Then, $b_{w}^{*} \geq \omega_{k k}$ is a weakly dominated strategy. $b_{w}^{*}<\omega_{k k}-\varepsilon$ is not an equilibrium, since firm $i \neq w$ then benefits from deviating to $b_{i}=b_{w}^{*}+\varepsilon$, since it will then obtain the assets and pay a price lower than its valuation of obtaining them. If $b_{w}^{*}=\omega_{k k}-\varepsilon$, and $b_{\varsigma}^{*} \in\left[\omega_{k k}-2 \varepsilon, \omega_{k k}-\varepsilon\right]$, then no incumbent has an incentive to deviate. By deviating to $b_{s}=b_{w}^{*}+\varepsilon$, an outsider's payoff decreases since $\omega_{s}<\omega_{k k}$. Accordingly, outsiders have no incentive to deviate and thus, $\mathbf{b}^{*}$ is a Nash equilibrium.

Let $\mathbf{b}=\left(b_{1}, b_{2}, \ldots, b_{n+u}\right)$ be a Nash equilibrium. Let outsider $h \neq i$ be the outsider with the highest bid, $b_{h} \leq \omega_{s}$. But then an incumbent $i$ will have the incentive to deviate to $b^{\prime}=\omega_{s}+\varepsilon$, since $\omega_{k s}>\omega_{s}$. This contradicts the assumption that $\mathbf{b}$ is a Nash equilibrium.

Inequality $\mathbf{I} 2$ Consider the equilibrium candidate $\mathbf{b}^{*}=\left(b_{1}^{*}, b_{2}^{*}, \ldots, b_{n+u}^{*}\right)$. Then, $b_{w}^{*} \geq \omega_{k k}$ is a weakly dominated strategy. $b_{w}^{*}<\omega_{k k}-\varepsilon$ is not an equilibrium since firm $i \neq w$ then benefits from deviating to $b_{i}=b_{w}^{*}+\varepsilon$, since it will then obtain the assets and pay a price lower than its valuation of obtaining them. If $b_{w}^{*}=\omega_{k k}-\varepsilon$, and $b_{\varsigma}^{*} \in\left[\omega_{k k}-2 \varepsilon, \omega_{k k}-\varepsilon\right]$, then no incumbent has an incentive to deviate. By deviating to $b_{s}=b_{w}^{*}+\varepsilon$, an outsider's payoff decreases since $\omega_{s}<\omega_{k k}$. Accordingly, an outsider has no incentive to deviate and thus, $\mathbf{b}^{*}$ is a Nash equilibrium.

Consider the equilibrium candidate $\mathbf{b}^{* *}=\left(b_{1}^{* *}, b_{2}^{* *}, \ldots, b_{n+u}^{* *}\right)$. Suppose outsider $w \neq i$ posted the highest bid. Then, $b_{w}^{*} \geq \omega_{s}$ is a weakly dominated strategy. $b_{w}^{*}<\omega_{s}-\varepsilon$ is not an equilibrium since outsider $s \neq w$ then benefits from deviating to $b_{s}=b_{w}^{*}+\varepsilon$, since it will then obtain the assets and pay a price lower than its valuation of obtaining them. If $b_{w}^{*}=\omega_{s}-\varepsilon$, and $b_{\varsigma}^{*} \in\left[\omega_{k k}-2 \varepsilon, \omega_{k k}-\varepsilon\right]$, then no outsider has an incentive to deviate. By deviating to $b_{i}=b_{w}^{*}+\varepsilon$, the incumbent's payoff decreases since $\omega_{k s}<\omega_{s}$. Accordingly, the incumbent has no incentive to deviate and thus, $\mathbf{b}^{* *}$ is a Nash equilibrium.

Inequality $\mathbf{I}$ Consider the equilibrium candidate $\mathbf{b}^{*}=\left(b_{1}^{*}, b_{2}^{*}, \ldots, b_{n+u}^{*}\right)$. Let us assume incumbent $i$ is the incumbent that has posted the highest bid and obtains the assets, and that firm $\varsigma \neq s$ is the incumbent with the second highest bid. Then, $b_{w}^{*}>\omega_{w w}$ is not an equilibrium since $w$ is benefits from lowering the bid and not acquiring the assets. $b_{w}^{*}<\omega_{k k}-\varepsilon$ is not an equilibrium since firm $i \neq w$ then benefits from deviating to $b_{i}=b_{w}^{*}+\varepsilon$, since it will then obtain the assets and pay a price lower than its valuation of obtaining them. If $b_{w}^{*}=\omega_{k k}-\varepsilon$, and $b_{\varsigma}^{*} \in\left[\omega_{k k}-2 \varepsilon, \omega_{k k}-\varepsilon\right]$, then no incumbent has an incentive to deviate. By deviating to $b_{s}=b_{w}^{*}+\varepsilon$, an outsider's payoff decreases since $\omega_{s}<\omega_{k k}$. Accordingly, the outsider has no incentive to deviate and thus, $\mathbf{b}^{*}$ is a Nash equilibrium.

Let $\mathbf{b}=\left(b_{1}, b_{2}, \ldots, b_{n+u}\right)$ be a Nash equilibrium. Let outsider $h \neq i$ be the outsider with the highest bid, $b_{h} \leq \omega_{s}$. But incumbent $i$ will have the incentive to deviate to $b_{i}^{\prime}=\omega_{s}+\varepsilon$, since $\omega_{k s}>\omega_{s}$. This contradicts the assumption that $\mathbf{b}$ is a Nash equilibrium. 
Inequality $\mathbf{I} 4$ Consider the equilibrium candidate $\mathbf{b}^{*}=\left(b_{1}^{*}, b_{2}^{*}, \ldots, b_{n+u}^{*}\right)$. Let us assume incumbent $w \neq s$ is the incumbent that has posted the highest bid and obtains the assets, and that firm $\varsigma \neq i$ is the outsider with the second highest bid. Then, $b_{w}^{*}>\omega_{s}$ is not an equilibrium since firm $w$ would then benefit from deviating to $b_{w}=\omega_{s} . b_{w}^{*}<\omega_{s}$ is not an equilibrium, since an outsider would then benefit by deviating to $b_{s}=b_{w}^{*}+\varepsilon$. If $b_{w}^{*}=\omega_{s}-\varepsilon$, then firm $w$ has no incentive to deviate. By deviating to $b_{i}^{\prime}>b_{w}^{*}$, incumbent $i$ 's payoff decreases since it must pay a price above its willingness to pay $\omega_{k k}$. Accordingly, firm $i$ has no incentive to deviate. Neither outsiders has an incentive to deviate since $b_{s}=b_{w}^{*}+\varepsilon$ is a dominated strategy. Thus, $\mathbf{b}^{*}$ is a Nash equilibrium.

Let $\mathbf{b}=\left(b_{1}, b_{2}, \ldots, b_{n+u}\right)$ be a Nash equilibrium. Let us assume outsider firm $w \neq i$ is the outsider that has posted the highest bid. The outsider will post a bid $b_{s} \leq \omega_{s}$. But incumbent $i$ will have the incentive to deviate to $b_{i}^{\prime}=\omega_{s}+\varepsilon$ since $\omega_{k s}>\omega_{s}$, which contradicts the assumption that $\mathbf{b}^{*}$ is a Nash equilibrium.

Inequalities $\mathbf{I 5}$ or $\mathbf{I} 6$ Consider the equilibrium candidate $\mathbf{b}^{*}=\left(b_{1}^{*}, b_{2}^{*}, \ldots, b_{n+u}^{*}\right)$. Let us assume outsider $w \neq i$ is the outsider that has posted the highest bid, where $b_{w}^{*}<\omega_{s}$. Then assume that $b_{w}^{*} \leq \omega_{s}-\varepsilon$ then another outsider will have an incentive to deviate to $b_{s}=b_{w}^{*}+\varepsilon$. Then assume that $b_{w}^{*}=\omega_{s}-\varepsilon$, it then directly follows that no firm has an incentive to deviate and thus, $\mathbf{b}^{*}$ is a Nash equilibrium.

Let $\mathbf{b}=\left(b_{1}, b_{2}, \ldots, b_{n+u}\right)$ be a Nash equilibrium. Let us assume incumbent firm $h \neq s$ is the firm with the highest bid. The incumbent will post a bid $b_{h} \leq \max \left\{\omega_{k s}, \omega_{k k}\right\}$. But outsider $s$ will have the incentive to deviate to $b_{s}^{\prime}=b_{h}+\varepsilon$ since $\omega_{s}>\max \left\{\omega_{k s}, \omega_{k k}\right\}$, which contradicts the assumption that $\mathbf{b}$ is a Nash equilibrium.

\section{B A Generalized Model: Trade Sales and IPOs}

So far we have assumed that private equity firms exit their investment via a trade sale. In this section we extend the model to allow for an exit through an initial public offering (IPO) in stage three. Formally, we will model an IPO as a sale of the restructured target to a firm outside the industry. It can also refer to selling the restructured target to dispersed shareholders or selling the firm to another private equity firm (secondary buyout) who ends up producing in the market.

The analysis shows that overinvestment in governance and restructuring will still occur when exit through an IPO is possible. However, when the focus is on exiting through an IPO, strategic product market effects matter less for the exit valuation and so governance and restructuring incentives are weaker as compared to when the focus is on exiting through a trade sale. Moreover, this extension is crucial for the analysis of optimal antitrust policy in the next section. With IPO as an exit mode the number of firms in the product market can be preserved after a buyout, but this occurs at the expense of weaker governance structures and lower restructuring efforts. Incumbents preemption incentives are, however, weaker as a result: buyouts followed by IPOs will meet less resistance from incumbents than buyouts followed by trade sales.

\section{B.1 Stage 4: Product Market Interaction}

The product market interaction stage must now allow for one more firm in the market (the right most "leg" in Figure 1). Suppose there are $u$ outsiders $(s \in\{1,2, . ., u\})$ interested in bidding for the restructured assets. These outsiders can represent other private equity firms, the same private equity firm who remains as the owner ("bidding for its own assets"), or incumbents from another industry. ${ }^{27}$ The key is that these outsiders do not have assets needed for production in this market. Using the ex-ante symmetry among incumbents, if an IPO occurs we distinguish between two firm types $h$ : a entering outsider $(h=S)$ and the non-acquiring incumbents $(h=N A)$. An incumbent of type $h=\{S, N A\}$ chooses an action $x_{h} \in R^{+}$ to maximize the direct product market profit $\Pi_{h}\left(x_{h}, \mathbf{x}_{-h}, r, s\right)$, where $l=s$ reminds us that a private equity firm bought the assets in stage one and exited through an IPO.

After an IPO, the Nash-equilibrium is given by

$$
\frac{\partial \Pi_{S}}{\partial x_{s}}\left(x_{s}^{*}, x_{-s}^{*} ; r, s\right)=0, \frac{\partial \Pi_{N A}}{\partial x_{N A}}\left(x_{N A}^{*}, x_{-N A}^{*} ; r, s\right)=0 .
$$

\footnotetext{
${ }^{27}$ The private equity firm is forced to sell the assets because of the fundamental temporary nature of private equity ownership (the private equity fund closes after a predetermined number of years).
} 
Table 2: Outcomes in the exit auction with IPOs.

\begin{tabular}{clcc}
\hline Inequality & Definition & Winning type & Acquisition price, $S^{3^{*}}$ \\
\hline$I 1$ & $\omega_{k k}>\omega_{k s}>\omega_{s}$ & $k$ & $\omega_{k k}$ \\
$I 2$ & $\omega_{k k}>\omega_{s}>\omega_{k s}$ & $k$ or $s$ & $\omega_{k k}, \omega_{s}$ \\
$I 3$ & $\omega_{k s}>\omega_{k k}>\omega_{s}$ & $k$ & $\omega_{k k}$ \\
$I 4$ & $\omega_{k s}>\omega_{s}>\omega_{k k}$ & $k$ & $\omega_{s}$ \\
$I 5$ & $\omega_{s}>\omega_{k k}>\omega_{k s}$ & $s$ & $\omega_{s}$ \\
$I 6$ & $\omega_{s}>\omega_{k s}>\omega_{k k}$ & $s$ & $\omega_{s}$ \\
\hline
\end{tabular}

Notes. This table describes the equilibrium ownership type ( $k$ or $s$ ) and the acquisition price $S^{3}$ for each possible ranking of the valuations $\omega$.

The reduced-form product market profits for the entering outsider are $R_{S}(r, s) \equiv \Pi_{S}\left(\left(x_{S}^{*}(r, s), x_{-S}^{*}(r, s) ; r, s\right)\right.$ and for non-acquirers they are $R_{N A}(r, s) \equiv \Pi_{N A}\left(\left(x_{S}^{*}(r, s), x_{-S}^{*}(r, s) ; r, s\right)\right.$. When an incumbent has acquired the target in stage one, or if a buyout in stage one is followed by an exit by trade sale in stage three, equation (1) applies with $n$ incumbents interacting in the product market. We then write incumbents reduced-form profits as $R_{A}(r, k)$ and $R_{N A}(r, k)$ to emphasize that the product market interaction takes place under incumbent ownership $(l=k)$ as opposed to when a private equity buyout took place in stage one $(l=s)$.

\section{B.2 Stage 3: The Exit Auction}

In the exit stage the $n$ incumbents and the $u$ outsiders simultaneously post bids, which are accepted or rejected by the private equity firm. We need to determine three valuations:

- The value to an outsider from buying the firm through an IPO is

$$
\omega_{s}=R_{S}(r, s)-G,
$$

where $G$ is a fixed cost undertaking an IPO (paid either by seller or the buyer).

- The value for an incumbent of deterring an IPO by preemptively acquiring the restructured assets is

$$
\omega_{k s}=R_{A}(r, k)-R_{N A}(r, s) .
$$

- The value for an incumbent to prevent a rival incumbent from acquiring the target from the private equity firm is

$$
\omega_{k k}=R_{A}(r, k)-R_{N A}(r, k)
$$

The outcome of the exit auction is presented in the following Lemma:

Lemma 2. The equilibrium ownership of the target and the acquisition price $S^{3}$ in stage one is given in Table 2.

Proof. See the Appendix.

Since incumbents on one hand are symmetric and outside investors are symmetric on the other hand, valuations $\omega_{k k}, \omega_{k s}$ and $\omega_{s}$ can be ordered in six different ways and the EOS is solved for each inequality I1-I6 in Table 2. Three types of ownership structures arise in equilibrium: the one where the private equity firm $s$ undertakes an IPO under I5 and I6, the one where the target firm is obtained by one of the incumbents, where the acquisition price is $S^{3^{*}}=\omega_{k k}$ under inequalities $I 1, I 2$ or $I 3$, and $S^{3^{*}}=\omega_{s}$ under inequality $I 4$. When $I 2$ holds, there exist multiple equilibria. In one equilibrium, an IPO occurs and no incumbent posts a bid above $\omega_{s}$. There is also an equilibrium where one of the incumbents obtains these assets at a price $\omega_{k k}-\varepsilon$ and another incumbent posts the second highest bid at $\omega_{k k}-2 \varepsilon$.

Let us solve the exit stage three in terms the level of restructuring $r$. We make the following simplifying assumption.

Assumption 2. $\frac{d R_{A}}{d r}-\frac{d R_{S}}{d r}>\frac{d R_{N A}(r, l)}{d r}$ and $\frac{d R_{N A}(r, l)}{d r}<0$ 
Figure 6: Optimal governance, restructuring and ownership with IPOs.

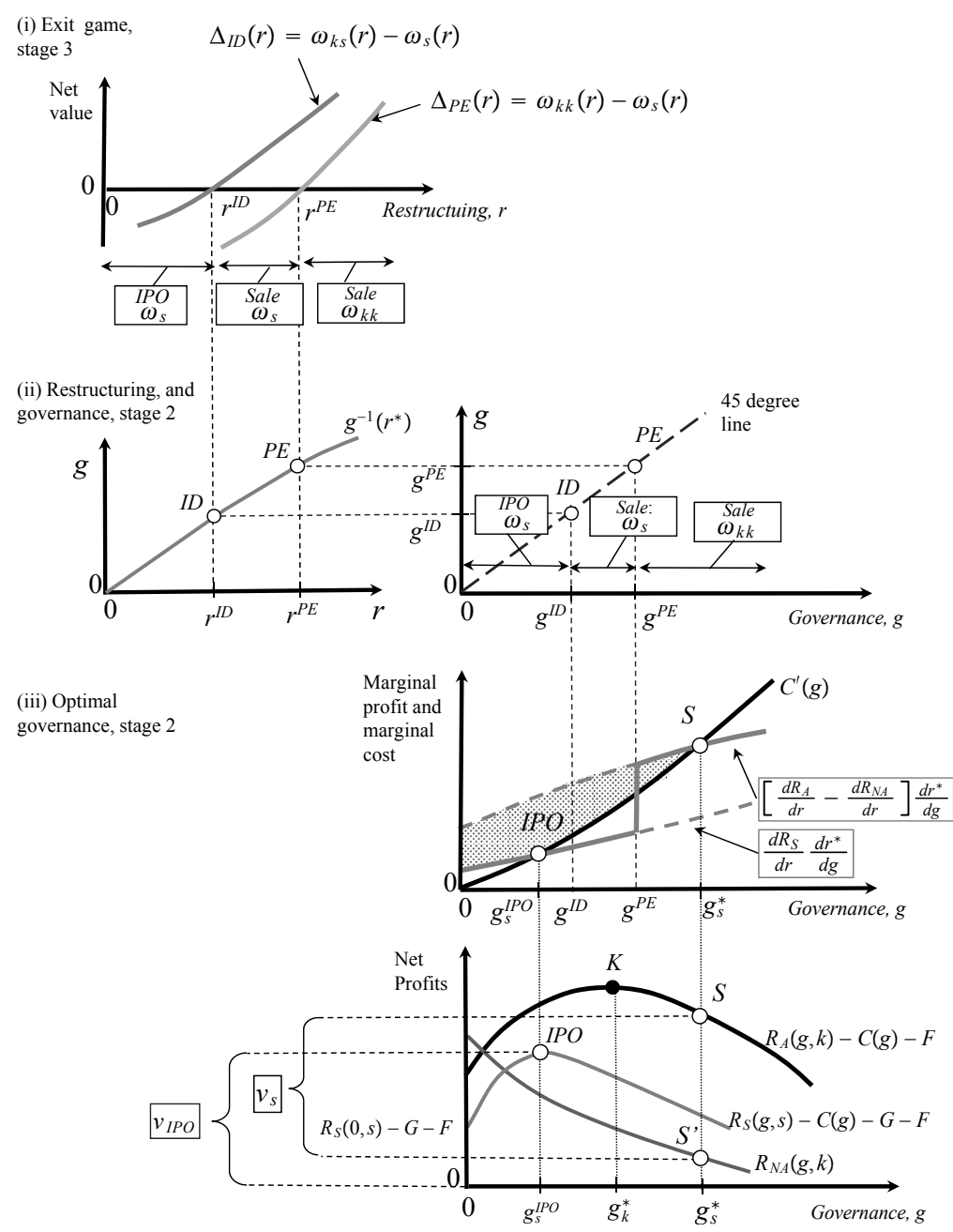

Notes. Part (i) of this figure illustrates that the exit game in stage three when IPOs are possible. For low restructuring $r$, IPOs are undertaken while for higher $r$ trade sales take place. Part (ii) illustrates governance intensity maps to restructuring intensity and thus how the exit mode (trade sale or IPO) is affected by governance intensity. Part (iii) displays how optimal governance intensity is set and how this in turns determine valuations in the initial acquisition auction.

This assumption tells us that the difference in the marginal effect on incumbent's profits $\left(d R_{A} / d r\right)$ and the marginal effect on the IPO profit $\left(d R_{S} / d r\right)$ is larger than the marginal effect on non-acquiring incumbent's profits $\left(d R_{N A}(r, l) / d r\right) .{ }^{28}$

Let us solve the exit stage three in terms of $r$. It is useful to define an incumbent's net value of deterring an exit by IPO as $\Delta_{I D}(r)=\omega_{k s}(r)-\omega_{s}(r)$, and an incumbent's net value of preempting a rival acquisition under exit from trade sale as $\Delta_{P E}(r)=\omega_{k k}(r)-\omega_{s}(r)$. Defining cut-off levels of restructuring $r^{P E}$ from $\Delta_{P E}\left(r^{P E}\right)=0$, and $r^{I D}$ from $\Delta_{I D}\left(r^{I D}\right)=0$, where $r^{I D}<r^{P E}$ since $\Delta_{I D}(r)>\Delta_{P E}(r)$ from $R_{N A}(r, k)>R_{N A}(r, s)$. We can then state the following Lemma:

Lemma 3. Assume that Assumption 2 holds and that $r^{I D}>r^{P E}>0$ exist. An IPO then takes place if $r \in\left(0, r^{E D}\right)$, a trade sale where the incumbent is driven by the incentive to deter an IPO at price

\footnotetext{
${ }^{28}$ Assumption 2 holds when the acquiring incumbent has a larger profit increase from restructuring than the profit increase when the target is placed on the market, $d R_{A} / d r \geq d R_{S} / d r$. This is reasonable since often the concentration is higher under incumbent ownership which results in a greater direct effect on costs when restructuring a larger firm (this dominates the standard strategic effect). In the LC-model of Example 1 without synergies from combining the target's assets and the acquiring incumbent's assets (i.e. with $\gamma=1$ and $c_{A}=c-r=c_{S}$ ), it can be shown that $d R_{A} / d r \geq d R_{S} / d r$ holds unless we approach monopoly. If synergies arise (i.e. with $\gamma>1$ and $\left.c_{A}=c-\gamma r<c_{S}\right), d R_{A} / d r \geq d R_{S} / d r$ will always hold if such synergies are sufficiently strong. Note, however, that Assumption 2 is milder and allows the profit increase from restructuring to be stronger under an IPO than for under incumbent ownership as long as this difference is not too large.
} 
$S^{3^{*}}=\omega_{s}(r)$ takes place for $r \in\left[r^{I D}, r^{P E}\right)$, and a trade sale under preemptive bidding competition at price $S^{3^{*}}=\omega_{k k}(r)$ occurs for $r \in\left[r^{P E}, r^{\max }\right)$.

The Lemma is illustrated in Figure 6(i). When little restructuring is conducted, $r \in\left(0, r^{I D}\right)$, the net value for deterring an outside acquisition is negative $\Delta_{I D}(r)=\omega_{k s}(r)-\omega_{s}(r)<0$, i.e. an incumbent's valuation $\omega_{k s}(r)$ is lower than the value of an IPO $\omega_{s}(r)$. In this region, the private equity firm will therefore choose to exit through an IPO. It can be shown that Assumption 2 holds and that $r^{I D}>$ $r^{P E}>0$ holds in the LC-model in Example 1.details of the analysis in

What happens if the level of restructuring increases? Differentiate $\Delta_{I D}(r)$ in $r$ to obtain

$$
\frac{d \Delta_{I D}}{d r}=\omega_{k s, r}^{\prime}-\omega_{s, r}^{\prime}=\frac{d R_{A}}{d r}-\frac{d R_{N A}(r, s)}{d r}-\frac{d R_{S}}{d r}>0
$$

An incumbent's value of deterring the outside firm from acquiring the target $\left(\omega_{k s}(r)\right)$ increases more than the IPO valuation $\left(\omega_{s}(r)\right)$ when the level of restructuring increases. From Assumption 2, both the first term in $\omega_{k s}(r)=R_{A}(r, k)-R_{N A}(r, s)$ as well as the first term in $\omega_{s}(r)=R_{S}(r, s)-G$ increases in $r$. However, since the profit of a non-acquirer $R_{N A}(r, s)$ decreases in $r$, an additional increase in the incumbent's valuation occurs such that $d \omega_{k s} / d r>d \omega_{s} / d r$. Thus, since an incumbent's net value of deterring an IPO $\Delta_{I D}(r)=\omega_{k s}-\omega_{s}$ is increasing in restructuring $r$, an incumbent acquisition at the acquisition price $S^{3}=\omega_{s}(r)$ occurs at $r=r^{I D}$ where $\Delta_{I D}\left(r^{I D}\right)=0$. Other incumbents will not preempt a rival acquisition in the region $r \in\left(r^{I D}, r^{P E}\right)$, since the net value of preemption is negative $\left(\Delta_{P E}(r)=\omega_{k k}-\omega_{s}<0\right)$. Hence the private equity firm will exit by a trade sale at the price $S^{3^{*}}=\omega_{s}(r)$ in this region.

What if restructuring increases even further? Since restructuring decreases the profit of a nonacquiring incumbent under an incumbent acquisition, the net value of preempting rivals also increases. Differentiating the net value of preemption $\Delta_{P E}$ in $r$ we obtain from Assumption 2

$$
\frac{d \Delta_{P E}}{d r}=\varpi_{k k, r}^{\prime}-\varpi_{e, r}^{\prime}=\frac{d R_{A}}{d r}-\frac{d R_{N A}(r, k)}{d r}-\frac{d R_{S}}{d r}>0 .
$$

As illustrated in Figure 6(i), when restructuring increases into the region $r \in\left[r^{P E}, r^{\max }\right)$ this leads to a strictly positive net value of preemption: $\Delta_{P E}(r)=\omega_{k k}-\omega_{s}>0$. This induces a bidding war between incumbents driving the equilibrium acquisition price above value of undertaking an IPO: $S^{3^{*}}=\omega_{k k}=$ $R_{A}(r, k)-R_{N A}(r, k)>\omega_{s}=R_{S}(r, k)-G$. The restructured firm is thus exited by a trade sale at the acquisition price $S^{3^{*}}=\omega_{k k}$.

\section{B.3 Stage 2: Governance and Restructuring}

Given the ownership of the target, a manager is hired to conduct restructuring. The utility of the manager is $U(r, g)=w(r, g)-e(r)$ from which we can use equations (4) and (5) to show that the manager's optimal choice of restructuring $r^{*}(g)$ is increasing in governance, $d r^{*} / d g>0$. Define reducedform profit functions $R_{S}(g, s) \equiv R_{S}\left(r^{*}(g), s\right)$, and $R_{N A}(g, s) \equiv R_{N A}^{I P O}\left(r^{*}(g), s\right)$ under exit by an IPO, and $R_{A}(g, k) \equiv R_{A}\left(r^{*}(g), k\right)$, and $R_{N A}(g, k) \equiv R_{N A}\left(r^{*}(g), k\right)$ under exit by a trade sale in stage three, or under a direct acquisition by an incumbent in stage one.

Let us now solve for the optimal choice of governance structure. We proceed in three steps. First, we show how the exit mode (IPO or trade sale) depends on the level of governance $(g)$. Second, we find what level of governance is chosen conditional on the exit mode $\left(g_{s}^{*}\right.$ and $\left.g_{s}^{I P O}\right)$, adding the cost of implementing the governance structure and undertaking restructuring $(C(g))$. Finally, we determine the optimal exit mode that maximizes the value of an exit.

\section{B.3.1 Exit Mode Given Governance.}

From equation (5), the optimal choice of restructuring by the manager $r^{*}(g)$ is a monotonic and increasing function in the intensity of governance $g$. We can then use its inverse $g^{-1}\left(r^{*}\right)$ to obtain the cutoffs $g^{I D}=g^{-1}\left(r^{I D}\right)$ and $g^{P E}=g^{-1}\left(r^{P E}\right)$. This is illustrated in the left panel of Figure 6(ii). As shown in the right panel of Figure 6(ii), these cutoffs allows us to restate Lemma 3 and derive the exit mode and the reward to exit as a function of the level of governance, $g$. Defining $\omega_{s}(g) \equiv R_{S}(g, s)-G$ as the reduced-form reward from exiting through an IPO in stage three, $\omega_{k s}(g)=R_{A}(g, k)-R_{N A}(g, s)$ as the reduced form IPO-deterring valuation, and $\omega_{k k}(g)=R_{A}(g, k)-R_{N A}(g, k)$ as the reduced-form preemptive valuation, we have the following Lemma: 
Lemma 4. An IPO takes place if $g \in\left(0, g^{I D}\right)$ with a reward $\omega_{s}(g)$ for the private equity firm, a trade sale where the incumbent buyer is driven by deterring an IPO at price $S^{3}=\omega_{s}(g)$ takes place for $g \in\left[g^{I D}, g^{P E}\right)$ and a trade sale driven by incumbents' incentive to preempt rivals occurs at price $S^{3}=\omega_{k k}(g)$ for $g \in\left[g^{P E}, g^{\max }\right)$.

\section{B.3.2 Optimal Governance.}

Lemma 4 says that under a low level of governance $\left(g \in\left(0, g^{I D}\right)\right)$ incumbents willingness to pay is low and therefore an exit by IPO will take place. Adding the cost of restructuring and governance $C(g)$, the optimal governance under an IPO is $g_{s}^{I P O}=\arg \max _{g}\left[\omega_{I P O}(g)-C(g)-(F-\Delta)\right]=\arg \max _{g}\left[R_{S}(g, s)-\right.$ $C(g)-G-(F-\Delta)$, with associated first-order condition:

$$
\frac{d R_{S}}{d g}=\frac{d R_{S}}{d r} \frac{d r^{*}}{d g}=C^{\prime}\left(g_{s}^{I P O}\right) .
$$

This choice is shown in point IPO in the upper panel of Figure 6(iii).

A higher level of governance $g \in\left[g^{I D}, g^{P E}\right)$ leads to an exit by a trade sale where incumbents pay the IPO valuation. In this region, the chosen level of governance is yet again given from equation (29), i.e. $g_{S}^{*}=g_{s}^{I P O}$. In the region $g \in\left[g^{P E}, g^{\max }\right)$, the private equity firm will choose $g_{s}^{*}=\arg \max _{g}\left[\omega_{k k}(g)-\right.$ $C(g)-(F-\Delta)]=\arg \max _{g}\left[R_{A}(g, k)-R_{N A}(g, k)-C(g)-(F-\Delta)\right]$, with the associated first-order condition (7). This is shown in point $S$ in the upper panel of Figure 6(iii). From Assumption 2, it follows that $d R_{A}(g, k) / d g-d R_{N A}(g, k) / d g-d R_{S}(g, s) / d g>0$ and from equation (29) and equation (7) we know that $g_{s}^{*}>g_{s}^{I P O}$ holds. Thus, to create bidding competition among incumbents, the level of governance is higher under exit by trade sale than under exit by an IPO $\left(g_{s}^{*}>g^{P E}>g_{s}^{I P O}\right)$.

Lemma 5. The level of governance and restructuring is higher under exit by trade sale than under exit by an IPO: $g_{s}^{*}>g_{s}^{I P O}$ and $r^{*}\left(g_{s}^{*}\right)>r^{*}\left(g_{s}^{I P O}\right)$.

Intuitively, the absence of preemptive competition in the exit stage (since exit occurs through an IPO) leads to reduced incentives to impose a strict governance structure and restructure the target. ${ }^{29}$

\section{B.3.3 Optimal Exit Mode.}

The optimal exit mode is now the one that maximizes the net value of an exit. To proceed, define the net value of doing an IPO as

$$
v_{I P O}=R_{S}\left(g_{s}^{I P O}, s\right)-C\left(g_{s}^{I P O}\right)-(F-\Delta), g_{s}^{I P O} \in\left[0, g^{I D}\right) .
$$

The value of a doing an exit by trade sale is then:

$$
v_{S}=\left\{\begin{array}{ll}
R_{S}\left(g_{s}^{*}, s\right)-C\left(g_{s}^{*}\right)-(F-\Delta) & \text { if } g_{s}^{*}=g_{s}^{I P O} \in\left[g^{I D}, g^{P E}\right) \\
R_{A}\left(g_{s}^{*}, k\right)-R_{N A}\left(g_{s}^{*}, k\right)-C\left(g_{s}^{*}\right)-(F-\Delta) & \text { if } g_{s}^{*}>g^{P E}
\end{array} .\right.
$$

To illustrate the choice of exit mode, suppose that $g_{S}^{*}>g^{P E}$ as shown in Figure 6(iii). Solve for the highest IPO cost $G$ consistent with IPO as exit mode. Using equation (30) and equation (31) in $v_{S}=v_{I P O}$ we obtain the exit condition

$$
\left.\bar{G} \equiv\left[R_{S}\left(g_{s}^{I P O}, s\right)-C\left(g_{s}^{I P O}\right)\right]-\left[R_{A}\left(g_{s}^{*}, k\right)-R_{N A}\left(g_{s}^{*}, k\right)-C\left(g_{s}^{*}\right)\right]\right]
$$

The left-hand side shows the maximum IPO cost consistent with exit by IPO. Since $C(0)=0$, it follows that

$$
R_{S}\left(g_{s}^{I P O}, s\right)-C\left(g_{s}^{I P O}\right)=R_{S}(0, s)+\int_{0}^{g_{s}^{I P O}}\left[d R_{S}(g, s) / d g-C^{\prime}(g)\right] d g .
$$

Moreover, $R_{A}(0, k)=R_{N A}(0, k)$ implies

$$
R_{A}\left(g_{s}^{*}, k\right)-R_{N A}\left(g_{s}^{*}, k\right)-C\left(g_{s}^{*}\right)=\int_{0}^{g_{s}^{*}}\left[d R_{A}(g, k) / d g-d R_{N A}(g, k) / d g-C^{\prime}(g)\right] d g .
$$

\footnotetext{
${ }^{29}$ While incentives to invest for private equity firms are stronger when they exit through trade sales than through IPOs, it is not clear if a private equity firm exiting through an IPO invests more than an incumbent acquiring the assets in stage one (one reason being a different numbers of competitors in the product market).
} 
Equation (32) can then be written as

$$
\begin{aligned}
\int_{0}^{g_{s}^{I P O}} & \underbrace{\left[\frac{d R_{A}(g, k)}{d g}-\frac{d R_{S}(g, s)}{d g}-\frac{d R_{N A}(g, k)}{d g}\right]}_{(+)} d g+ \\
& \int_{g_{s}^{I P O}}^{g_{s}^{*}} \underbrace{\left[\frac{d R_{A}(g, k)}{d g}-\frac{d R_{N A}(g, k)}{d g}-C^{\prime}(g)\right]}_{(+)} d g=R_{S}(0, s)-G .
\end{aligned}
$$

The first term on the right hand side shows the level of profits that can be made under IPO without inducing restructuring through improved governance. The left hand side shows how much profits could be increased by the stronger governance chosen under exit by trade sale with bidding competition between incumbents, $\left(g_{s}^{*}>g_{s}^{I P O}\right)$. The first term shows the increment in profit from obtaining a higher marginal revenue in a trade sale for the level of governance associated with an $\operatorname{IPO}\left(g_{s}^{I P O}\right)$. The second term adds the increase in the profit from investing additionally in restructuring by choosing the higher level of governance in a trade sale $\left(g_{s}^{*}>g_{s}^{I P O}\right)$. Thus, an exit by trade sale is more likely the larger is the level of governance in a trade sale relative to an IPO. The sum of these two terms is shown by the shaded areas in Figure 6(iii).

In terms of empirical predictions, we can note the following. If Assumption 2 holds, if $g_{s}^{*}>g^{P E}$, and if a private equity firm has acquired the target in stage one, then the private equity firm will exit by trade sale when IPO costs are high, the marginal cost of governance is low and when governance (and subsequent restructuring) can significantly affect the target's as well as rival firm's net profits. Moreover, buyouts with little performance improvements in the target should predominately occur when exit takes place by an IPO.

Note that trade-sales are common exit routes for private equity firms. Kaplan and Strömberg (2009) report that $38 \%$ of all realized exits world-wide are trade sales and only $14 \%$ are IPOs. A part of the explanation, aside from product market effects and potential synergies between incumbents' and target's assets, is that IPO costs are substantial: Chen and Ritter (2000) document that the gross spreads (or underwriting discounts) in the US is commonly around seven percent.

\section{B.4 Stage 1: The Acquisition Auction}

We are now set to solve the acquisition auction in stage one when private equity firms can exit in stage three by a trade sale or IPO. Due to the bidding competition, private equity firms will always bid $\max \left(v_{I P O}, v_{s}\right)$, and upon winning, exit in stage three with the exit mode that gives the highest reward. To proceed, let us define $E\left[\pi^{3}\right]$ as the expected net profit of participating in the late auction. Note that for $g_{S}^{*} \in\left[g^{I D}, g^{P E}\right.$ ) (under I4), we have

$$
\left.\mathrm{E}\left[\pi^{3}\right]=\frac{1}{n}\{R_{A}\left(g_{s}^{I P O}, k\right)-\underbrace{\left[R_{S}\left(g_{s}^{I P O}, s\right)-G\right]}_{S^{3^{*}}=\omega_{s}}\}+\left(\frac{n-1}{n}\right) R_{N A}\left(g_{s}^{I P O}, k\right)\right\} .
$$

where $\frac{1}{n}$ is the probability of becoming the acquirer and $\frac{n-1}{n}$ is the probability of becoming a nonacquirer. For $g_{S}^{*} \in\left[0, g^{I D}\right), E\left[\pi^{3}\right]=R_{N A}\left(g_{s}^{I P O}, s\right)$ and for $g_{S}^{*}>g^{P E}, E\left[\pi^{3}\right]=R_{N A}\left(g_{s}^{*}, k\right)$ due to bidding competition between symmetric incumbents. We can then complete our set of valuations to include an incumbent's value of deterring when also an exit by IPO is possible as:

$$
v_{k z}=\left\{\begin{array}{c}
v_{k I P O}=R_{A}\left(g_{k}^{*}, k\right)-C\left(g_{k}^{*}\right)-F-R_{N A}\left(g_{s}^{I P O}, s\right), g_{S}^{*} \in\left[0, g^{I D}\right), \\
v_{k s}=R_{A}\left(g_{k}^{*}, k\right)-C\left(g_{k}^{*}\right)-F-\mathrm{E}\left[\pi^{3}\right], g_{S}^{*} \in\left[g^{I D}, g^{P E}\right), \\
v_{k s}=R_{A}\left(g_{k}^{*}, k\right)-C\left(g_{k}^{*}\right)-F-R_{N A}\left(g_{s}^{*}, k\right), g_{S}^{*}>g^{P E}
\end{array}\right.
$$

Define the optimal exit mode in stage three for private equity firms, given private equity ownership in stage one, as:

$$
l= \begin{cases}s & \text { if } v_{s}>v_{I P O} \\ I P O & \text { if } v_{s} \leq v_{I P O}\end{cases}
$$

We can then derive the following Lemma:

Lemma 6. The equilibrium ownership and the acquisition price $S^{1}$ in stage one is given in Table 3. 
Table 3: Equilibrium ownership structure and the acquisition price with IPOs

\begin{tabular}{cccc}
\hline \multicolumn{4}{l}{ For $l \in\{s, I P O\}$ in equation $(38):$} \\
Inequality & Definition & Winning type & Acquisition price, $S^{1^{*}}$ \\
\hline$I 1$ & $v_{k k}>v_{k l}>v_{l}$ & $k$ & $v_{k k}$ \\
$I 2$ & $v_{k k}>v_{l}>v_{k l}$ & $k$ or $l$ & $v_{k k}, v_{l}$ \\
$I 3$ & $v_{k l}>v_{k k}>v_{l}$ & $k$ & $v_{k k}$ \\
$I 4$ & $v_{k l}>v_{l}>v_{k k}$ & $k$ & $v_{l}$ \\
$I 5$ & $v_{l}>v_{k k}>v_{k l}$ & $l$ & $v_{l}$ \\
$I 6$ & $v_{l}>v_{k l}>v_{k k}$ & $l$ & $v_{l}$ \\
\hline
\end{tabular}

Notes. This table describes the equilibrium ownership type $(k$ or $l)$ and the acquisition price $S^{1}$ for each possible ranking of the valuations $v$.

Proof. The proof is identical to the proof of Lemma 2 when replacing (i) $\omega$ with $v$; (ii) $s$ with $l$ determined by equation (38), and (iii) the bidders are now $y \in\{i \in\{1,2, . ., n\}, j \in\{1,2, . ., m\}\}$.

From Lemma 6 and 5, we have the following lemma:

Lemma 7. Suppose that $g_{s}^{*}>g^{P E}$ such that trade sales occur under bidding competition. Then, buyouts exited through IPOs can occur in equilibrium when buyouts exited through trade sales would be preempted by incumbents. Buyouts exited through IPOs instead of trade sales will lead to less overinvestment and thus incentives for incumbents to preemptively outbid private equity firms are reduced.

To prove Lemma 7, let us derive the smallest advantage in fixed restructuring cost needed to have an $\operatorname{IPO}(\tilde{\Delta})$. From the IPO-condition $\left(v_{I P O}(\tilde{\Delta}) \equiv v_{k I P O}\right)$ we obtain:

$$
\tilde{\Delta}=R_{A}\left(g_{k}^{*}, k\right)-C\left(g_{k}^{*}\right)-R_{N A}\left(g_{s}^{I P O}, s\right)-\left[R_{S}\left(g_{s}^{I P O}, s\right)-C\left(g_{s}^{I P O}\right)-G\right] .
$$

Let us compare $\tilde{\Delta}$ to the smallest restructuring advantage needed to have a buyout for trade sale $(\bar{\Delta})$ defined in the preemption condition $v_{k s}=v_{s}(\bar{\Delta})$ from equation (12). This gives, after some manipulation,

$$
\bar{\Delta}-\tilde{\Delta}=v_{I P O}-v_{s}+R_{N A}\left(g_{s}^{I P O}, s\right)-R_{N A}\left(g_{s}^{*}, s\right) .
$$

To get a feel for how the equilibrium ownership structure is determined, consider Figure 7, which depicts the equilibrium ownership structure over the space of the fixed cost advantage of private equity firms $\Delta \geq 0$ and the fixed IPO cost $G \geq 0$. The horizontal locus $\bar{G}$ is the exit condition (with $\bar{G}>0$ assumed), defined from $v_{s}=v_{I P O}$ in equation (32). For $G<\bar{G}$, the private equity firm will exit by an IPO in stage three, whereas for $G \geq \bar{G}$ the exit takes place by a trade sale.

Consider first the region where exit would take place through a trade sale $(G \geq \bar{G})$. The vertical locus $\bar{\Delta}$ is the preemption condition and again shows the fixed costs advantage required by private equity firms just to outbid incumbents $\left(v_{s}=v_{k s}\right)$. For $\Delta>\bar{\Delta}$ a private equity firm will outbid the incumbents and hence in the North-East region in Figure 7, the target is acquired in stage one by a private equity firm paying the price $S^{1^{*}}=v_{s}$ (followed by an exit by a trade sale). In the North-west-region, where $\Delta \leq \bar{\Delta}$, an incumbent preempts private equity firms in stage one paying the price $S^{1^{*}}=v_{s}$.

Consider then IPO costs low enough to generate exits by IPO in stage three $(G<\bar{G})$. The first term in equation (40) must be positive because $G<\bar{G}$ implies $v_{I P O}>v_{s}$. Then, from Lemma 5 , exit by a trade sale implies a stronger governance structure than exit by IPO $\left(g_{s}^{*}>g_{s}^{I P O}\right)$. It follows that if $g_{s}^{*}-g_{s}^{I P O}$ is sufficiently large, a non-acquiring incumbent is worse off under a trade sale despite the lower concentration under an IPO $\left(R_{N A}\left(g_{s}^{I P O}, s\right)>R_{N A}\left(g_{s}^{*}, s\right)\right)$. But then $\bar{\Delta}>\tilde{\Delta}$ such that a smaller advantage is required under an IPO to outbid incumbents. Thus, buyouts for IPO meet less resistance from incumbents than buyouts for trade sale. This can also be seen in Figure 7 noting that the locus for the IPO condition which is the upward sloping line which intersects $\Delta$-axis at $\tilde{\Delta}(0)<\bar{\Delta}$. Below both the IPO and exit condition, the target will be acquired by a private equity firm at the price $S^{1^{*}}=v_{I P O}$. Since the IPO condition is upward sloping it follows that an IPO can occur when trade sales would be preempted even for positive IPO costs $(G)$. Above the IPO condition but below the exit condition, the target would be acquired by an incumbent. The price is either $v_{I P O}$ or $v_{k k}$ depending on which is greater. 
Figure 7: The Ownership equilibrium in stage one of the generalized model.

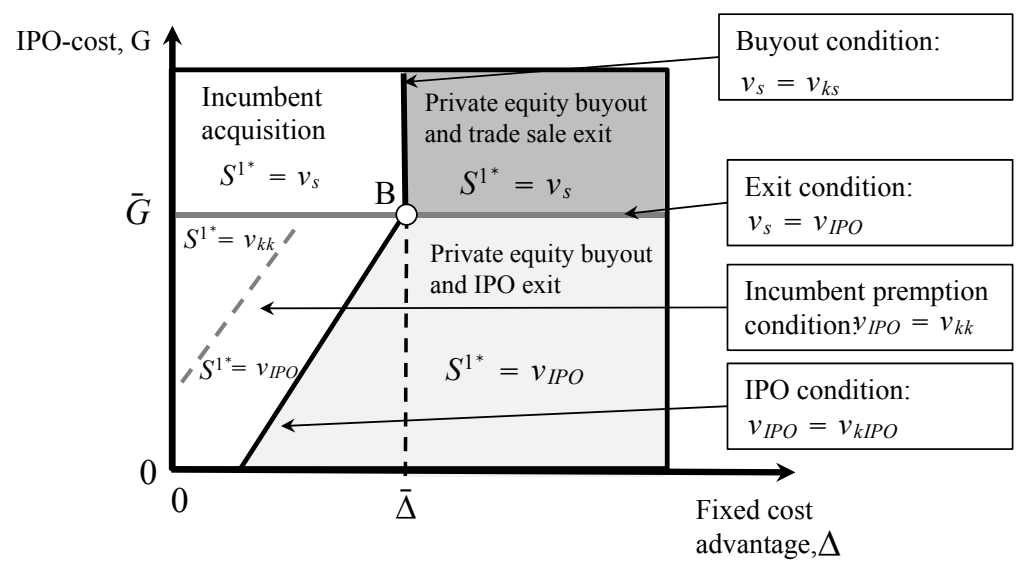

Notes. The figure illustrates how the equilibrium outcome of stage one of the generalized model depends on the IPO cost $G$ and the fixed restructuring advantage $\Delta$.

Intuitively, Lemma 7 underscores that private equity buyouts that preserve competition in the market meet less resistance from incumbents than private equity buyouts that lead to a concentration in the industry. The natural tendency towards preserving the number of firms in the industry comes from the overinvestment incentives private equity firms face. Incumbents realize that if the buyout will lead to an IPO instead of to a trade sale, reducing the number of firms in the industry, overinvestment incentives will be lower and hence they will have less to fear from letting a private equity firm acquire the target.

\section{B.5 Allowing the target to remain on the market}

It is now easy to extend the model with target's decision to sell in stage 1. Noting that the target will never sell its assets for a lower price than $v_{t}$ and that the bidding competition between symmetric private equity firms implies that private equity firms always bid $\max \left\{v_{s}, v_{I P O}\right\}$, the acquisition game in stage one can be solved applying the technique used in proving Lemma 6 . The acquisition game in stage one can be solved by applying Lemma 6 and replacing equation (38) with

$$
l= \begin{cases}s & \text { if } v_{s}>\max \left\{v_{I P O}, v_{t}\right\} \\ I P O & \text { if } v_{I P O}>\max \left\{v_{s}, v_{t}\right\} \\ t & \text { if } v_{t}>\max \left\{v_{s}, v_{I P O}\right\}\end{cases}
$$

where $l$ denotes ownership in the exit auction in stage three. where $v_{t}$ is the reservation price of the target defined in the text.

\section{Extensions}

\section{C.1 The differentiated product multi-plant model}

Our results do not depend on the mode of product market competition (prices or quantities). To see this, consider another example of a product market model that fulfills Assumption 1: the differentiated product multi-plant model. Let each firm initially own and produce one product and let the inverse demand of a product be $P_{j}=a-q_{j}-\tau q_{-j}$, in which $\tau \in[0,1]$ is the degree of product substitutability ( $\tau=0$ implies a monopoly and $\tau=1$ implies homogenous goods), $q_{j}$ is the output of product $j$ and $q_{-j}$ is the output of the other products. The product market profit for a firm with product $j$ is $\Pi_{j}=\left(P_{j}-c_{j}\right) q_{j}$. Dividing up in firm types, marginal costs are (without synergies):

$$
c_{A}=c-\bar{k}, \quad c_{N}=c-\bar{k}, \quad c_{T}=c-r,
$$

where $c_{T}$ is the marginal cost of the target and $\bar{k}$ represents firm-specific assets. The acquirer will now own two products (its own product and the target's product). The Nash-Cournot equilibrium $\mathbf{q}^{*}=\left(q_{h}^{*}, q_{-h}^{*}\right)$ 
is then determined from the first-order conditions $\frac{\partial\left(\Pi_{A}+\Pi_{T}\right)}{\partial q_{T}}=0$ and $\frac{\partial\left(\Pi_{A}+\Pi_{T}\right)}{\partial q_{A}}=0$ for the acquirer, and $\frac{\partial \Pi_{N}}{\partial q_{N}}=0$ for a non-acquirer. We can then define $R_{A}=\left[P_{A}\left(\mathbf{q}^{*}\right)-c_{A}\right] q_{A}^{*}+\left[P_{T}\left(\mathbf{q}^{*}\right)-c_{T}\right] q_{T}^{*}$ as the associated reduced-form profit function for the acquirer and $R_{N}=\left[P_{N}\left(\mathbf{q}^{*}\right)-c_{N}\right] q_{N}^{*}$ as the reducedform profit function for a non-acquirer. The differentiated product multi-plant model can also be solved for Bertrand competition. The inverse demand function in $P_{j}=a-q_{j}-\tau q_{-j}$ is inverted into direct demand, $q_{j}(\mathbf{p}, \eta)$, with $\mathbf{p}=\left(p_{j}, p_{-j}\right)$. Dividing into firm types, the direct profit is $\Pi_{h}=\left(p_{h}-c_{h}\right) q_{h}(\mathbf{p})$. Let $\mathbf{p}^{*}=\left(p_{h}^{*}, p_{-h}^{*}\right)$ be the Nash-Bertrand equilibrium from the first-order conditions $\frac{\partial\left(\Pi_{A}+\Pi_{T}\right)}{\partial p_{T}}=0$ and $\frac{\partial\left(\Pi_{A}+\Pi_{T}\right)}{\partial p_{A}}=0$ for the acquirer, and $\frac{\partial \Pi_{N}}{\partial p_{N}}=0$ for a non-acquirer. From these conditions we can define $R_{A}=\left[p_{A}^{*}-c_{A}\right] q_{A}\left(\mathbf{p}^{*}\right)+\left[p_{T}^{*}-c_{T}\right] q_{T}\left(\mathbf{p}^{*}\right)$ and $R_{N}=\left[p_{N}^{*}-c_{N}\right] q_{N}\left(\mathbf{p}^{*}\right)$ as the associated reduced-form profit functions. Assumption 1 holds for these profit functions.

\section{C.2 Exogenous Variable Restructuring Cost Advantages}

Suppose now that private equity firms not only have an advantage $\Delta$ in fixed restructuring costs, but that they also have an advantage in variable restructuring costs such that $k_{s}^{\prime}(r)<k_{k}^{\prime}(r)$. This implies that we have $C^{k}(g)=c(g)+k_{k}\left(r^{*}(g)\right)$ and $C^{s}(g)=c(g)+k_{s}\left(r^{*}(g)\right)$, with $d C^{k} / d g>d C^{s} / d g>0$.

If private equity firms have lower variable costs of restructuring, they have even stronger incentives to improve the governance structure, as $g_{k}^{*}$ is determined implicitly from $\left(d R_{A} / d r\right)\left(d r^{*} / d g\right)=d C^{k} / d g$ and $g_{s}^{*}$ from $\left[d R_{A} / d r-d R_{N A} / d r\right]\left(d r^{*} / d g\right)=d C^{s} / d g$. Hence, we still have that $g_{s}^{*}>g_{k}^{*}$ and $r^{*}\left(g_{s}^{*}\right)>r^{*}\left(g_{k}^{*}\right)$.

But even absent strategic product market effects on the trade sale price, private equity firms will now choose stronger governance structures and induce more restructuring. Second, in the same way as fixed variable cost advantages counteracts the preemptive acquisition motive incumbents have, variable cost advantages in restructuring will allow private equity firms to outbid incumbents in the initial acquisition auction in stage one even absent any fixed cost advantage $\Delta$.

\section{C.3 Managerial Ownership Combined with a Fixed Wage}

In stage two above we provided managerial ownership as an example of a governance structure. But what if the manager is offered both a fixed wage $b$ and a share $g$ of the firm? Suppose that the managers utility function is $u(W(b, g), r)=-e^{-\eta[W(b, g)-e(r)]}$ in which $\eta$ measures the degree of risk aversion. The restructuring effort undertaken by the manager is observed but is not verifiable and cannot be contracted on. The manager is therefore offered a linear contract $\{b, g\}$ consisting of a fixed wage $b$ and a share $g$ of the product market profits net of restructuring costs: $W(b, g)=b+g\left[R_{A}(r)-F\right]$. The restructuring costs for the firm are uncertain and given by $F-\lambda$, with $\lambda \sim N\left(0, \sigma^{2}\right)$. We need to have profits net of restructuring costs now to ensure that the manager bears the risk associated with restructuring.

Consider the manager's decision on how much restructuring $(r)$ to undertake given the contract $\{b, g\}$. The manager exerts an effort to restructure the target by maximizing expected utility $\mathrm{E}[u(W(b, g), r)]=$ $-e^{-\eta[W(b, g)-e(r)]} \mathrm{E}\left[e^{-\eta \mu \lambda}\right]$. We can separate out the stochastic term $\lambda$, and since $\lambda \sim N\left(0, \sigma^{2}\right)$ it follows that $\mathrm{E}\left[e^{-\eta g \lambda}\right]=e^{-\eta^{2} g^{2} \frac{\sigma^{2}}{2}}$. Defining $\Omega(g)=\eta g^{2} \frac{\sigma^{2}}{2}$ as the risk premium given to the manager, it follows that the optimal restructuring is defined as

$$
r^{*}=\arg \max _{r} \mathrm{E}[u(W(b, g), r)]=\arg \max _{r}\left[b+g\left[R_{A}(r)-F\right]-\Omega(g)-e(r)\right] .
$$

It is now apparent that this is just a special case where $w(r, g)=b+g\left[R_{A}(r)-F\right]-\Omega(g)$. Since $w_{r g}^{\prime \prime}=R_{A}^{\prime}(r)>0$, we have $d r^{*} / d g>0$.

So how does the cost function for the governance structure $g$ look? The optimal fixed wage $b^{*}$ can be pinned down from the participation constraint $W\left(b^{*}, g\right)-e\left(r^{*}(g)\right)-\Omega(g)=\bar{w}$. Hence, the wage to pay as a function of $g$ is $W\left(b^{*}, g\right)=\bar{w}+e\left(r^{*}(g)\right)+\Omega(g)$. The cost of governance can then be rewritten as $c(g)=\bar{w}+e\left(r^{*}(g)\right)+\Omega(g)$ with $d c(g) / d g=e^{\prime}\left(r^{*}(g)\right) d r^{*} / d g+\Omega^{\prime}(g)>0$. The rest of our results then follow.

\section{C.4 Incentive Contracts on the Trade Sale Price}

In stage two above, we provided managerial ownership as an example of a governance structure. However, the assumption was that both private equity firms and incumbents offer the manager a share of product market profits. This enables us to compare the intensity of the compensation contract for the two ownership types. It is also consistent with many contracts used in practice as managers in private equity 
backed firms are often required to remain with the target (or are forced to keep their stocks in the firm) post exit to reduce problems associated with, for example, window dressing.

However, if the manager is allowed to sell all shares at the time of exit, the relevant share for the manager is a share of the trade sale price instead of a share of the product market profits. We then have the following situation:

- Buyout in stage one: $w^{s}(r, g)=g\left(R_{A}(r)-R_{N A}(r)\right)$, with $w_{r g}^{s \prime \prime}=R_{A}^{\prime}(r)-R_{N A}^{\prime}(r)>0$ and $d r_{s}^{*} / d g>0$. The cost for the private equity firm is $c^{s}(g)=g\left[R_{A}\left(r^{*}(g)\right)-R_{N A}\left(r^{*}(g)\right)\right]$ with $d c^{s}(g) / d g=g\left[\frac{d R_{A}}{d r}-\frac{d R_{A}}{d r}\right] \frac{d r^{*}}{d g}+\left[R_{A}\left(r^{*}(g)\right)-R_{N A}\left(r^{*}(g)\right)\right]>0$. We have $C^{s}(g)=c^{s}(g)+k(r(g))$, with $d C^{s} / d g>0$.

- Incumbent acquisition in stage one: $w^{k}(r, g)=g R_{A}(r)$, with $w_{r g}^{k \prime \prime}=R_{A}^{\prime}(r)>0$ and $d r_{k}^{*} / d g>0$. The cost for the incumbent is $c^{k}(g)=g R_{A}\left(r^{*}(g)\right)$ with $d c^{k}(g) / d g=g \frac{d R_{A}}{d r} \frac{d r^{*}}{d g}+R_{A}\left(r^{*}(g)\right)>0$. We have $C^{k}(g)=c^{k}(g)+k(r(g))$, with $d C^{k} / d g>0$.

Since it now holds that $w^{s}(r, g) \neq w^{k}(r, g)$ and $C^{s}(g) \neq C^{k}(g)$ it need not be that $g_{s}^{*}>g_{k}^{*}$ and $r_{s}^{*}\left(g_{s}^{*}\right)>r_{k}^{*}\left(g_{k}^{*}\right)$ holds. To see this, note first that $w_{r g}^{s \prime \prime}>w_{r g}^{k \prime \prime}>0$. This says that the manager in a private equity backed firm receiving a share of the trade sale price responds more strongly to an increase in governance than a manager in an incumbent acquisition (and that both managers respond to increased governance by increasing restructuring activities). This opens the possibility that a private equity firm can not implement as strong governance measures to induce restructuring because the manager responds more strongly simply because he or she is getting a share of the trade sale price. It is thus possible to have $g_{s}^{*}<g_{k}^{*}$, but $r_{s}^{*}\left(g_{s}^{*}\right)>r_{k}^{*}\left(g_{k}^{*}\right)$. In general, this occurs if $g_{k}^{*}$ determined implicitly from the first-order condition under an incumbent acquisition:

$$
\frac{d R_{A}}{d r} \frac{d r_{k}^{*}}{d g}=\frac{d C^{k}\left(g_{k}^{*}\right)}{d g}
$$

is larger than $g_{s}^{*}$ determined from the first-order condition under a private equity buyout:

$$
\left[\frac{d R_{A}}{d r}-\frac{d R_{N A}}{d r}\right] \frac{d r_{g}^{*}}{d g}=\frac{d C^{s}\left(g_{s}^{*}\right)}{d g}
$$

Thus, private equity firms always induce more restructuring than incumbents $\left(r_{s}^{*}\left(g_{s}^{*}\right)>r_{k}^{*}\left(g_{k}^{*}\right)\right)$, but if the contract to the manager is on the trade sale price, private equity firms need not necessarily implement stronger governance structures to induce more restructuring $\left(g_{s}^{*} \lesseqgtr g_{k}^{*}\right)$.

\section{C.5 Other Selling Mechanisms}

In the analysis, we have assumed that the seller of the target uses a first-price auction. We believe this auction set-up accurately approximates bidding competition in oligopolies. But some possibilities for creating additional rents are neglected as a result. More generally, Jehiel et al. (1999) show that sophisticated mechanisms are needed to maximize revenues in auctions with externalities; it could be that all firms in the market need to provide transfers to the seller. As pointed out by Jehiel and Moldovanu (2000), the seller needs an unrealistically strong commitment power, making such mechanisms impractical. One potential feasible way for the target to extract more rents is to threaten to commit to sell to a private equity firm. An incumbent would be willing to pay $v_{k s}$ in the initial acquisition auction, which would give the target larger proceeds compared to when it sells to a private equity firm (since $\left.S^{1}=v_{s}<v_{k s}\right)$.

One way of achieving this would be to state a reservation price of $v_{k s}$, but this will not work unless the target can restructure its own assets. The reason is that if the reservation price is $v_{k s}>v_{s}$, private equity firms will not participate in the auction and the threat of selling to one of them will not be credible. The maximum willingness to pay for incumbents would then be $v_{k k}$ and the target would be forced to charge a reservation price lower than $v_{k s}$. 